\title{
Are they telling the truth? Revealing hidden traits of satisfaction with a public bike sharing service
}

\section{Dr Giancarlo Manzi \& Mr Giorgio Saibene}

To cite this article: $\operatorname{Dr}$ Giancarlo Manzi \& Mr Giorgio Saibene (2017): Are they telling the truth? Revealing hidden traits of satisfaction with a public bike sharing service, International Journal of Sustainable Transportation, DOI: 10.1080/15568318.2017.1353186

To link to this article: http://dx.doi.org/10.1080/15568318.2017.1353186

Accepted author version posted online: 12 Jul 2017.

Submit your article to this journal $\asymp$

View related articles $\nearrow$

View Crossmark data $₫$ 
International Journal of Sustainable Transportation

Are they telling the truth? Revealing hidden traits of satisfaction with a public bike sharing service

Dr Giancarlo Manzi ${ }^{1}$, Mr Giorgio Saibene ${ }^{2}$

Universita degli Studi di Milano, Milano, 20122 Italy

${ }^{1}$ Corresponding Author Email: giancarlo.manzi@unimi.it

${ }^{2}$ Corresponding Author Email: Email: giorgio.saibene@unimi.it

\section{Keywords}

Public transport; Bike sharing; Satisfaction indicators; Quality perception; Nonlinear Principal Component Analysis

Abstract. Public bike-sharing systems are an emerging mode of transportation introduced by municipalities to solve congestion problems in metropolitan areas, especially when integrated with other types of transportation. In the last years, the number of public bike sharing services is constantly on the rise all over the world, and generally the overall satisfaction with them is high. However, satisfaction with public services is driven by mechanisms that can differ from those in the private sector. It is important to establish to what extent a high satisfaction is genuine or simply ephemeral. Even "old" public services (like public transportation) become "gold" when accompanied by the introduction of new technologies. In this paper we analyse this phenomenon using data from a satisfaction web-survey conducted among customers of the public bike sharing system 'BikeMi' in Milan, Italy, in a period when mobile technologies have been introduced to speed up the service. On simply analysing the responses to satisfaction questions, satisfaction resulted very high. However, our aim was to look for potential 'darker' sides of the service by 


\section{ACCEPTED MANUSCRIPT}

detecting possible hidden satisfaction components. To this purpose, we used the Nonlinear Principal Components Analysis, which is particularly powerful in this sense. A simple textual analysis was also performed as a validating test. Results from our analysis indicated that satisfaction is flawed by a set of factors like the mechanics of the bikes, the picking and dropping system, and the apps used to organize the service. Less concern was detected for more general aspects of the service. 


\section{ACCEPTED MANUSCRIPT}

\section{Introduction}

Is it possible to turn the bicycle into one of the fastest, most convenient, modern and reliable means of transport? Cycling is one of the slowest and oldest human-conceived modes of transportation, but in the last years has received renewed attention as it is considered environmentally friendly, beneficial for the health, and, above all, a sound alternative to the car in highly congested cities. Consequently, bicycle usage has constantly increased. With the spread of the economic crisis in the last years, socioeconomic factors are increasingly emerging as major determinants of bike usage (Smith \& Kauermann, 2011).

\subsection{The recent bike usage surge and a brief history of public bike-sharing systems}

Statistics on bike production, traffic, consumption and sales are prevalently obtained via estimation, even if some countries produce reliable statistics through their official national transportation surveys. In the United States bike usage has consistently increased in the last years. Evidence from the U.S. National Household Travel Survey shows that the average American made two more bike trips in 2009 than in 2001, covering 5 more miles per year (Pucher et al. 2011) ${ }^{1}$. Data from the American Community Survey show that from 2000 to 2014 bicycle commuting has seen 62\% growth nationwide, with 904,463 bike commuters in 2014 (League of American Bicyclists, 2014). A similar growth (61\%) was reported between 2000 and 2012 for the number of U.S. workers who travelled to work by bicycle, a larger percentage increase than that of any other commuting mode (American Community Survey, 2014). Furthermore, the surge in bike sales and usage is strikingly increasing as long as innovation plays

\footnotetext{
${ }^{1}$ A new US National Household Travel Survey has been planned for 2016-17, but results are not available until early 2018 (http://nhts.ornl.gov, accessed on June 28th, 2017).
} 


\section{ACCEPTED MANUSCRIPT}

a more relevant role in the bike market. For example, the electronic bike has experienced a real boom in the last years: China's e-bike annual production has grown from around 1,600,000 units in 2002 to 36,950,000 units in 2013 (Fishman et al., 2014; Jamerson \& Benjamin, 2015; Zhang et al., 2014); sales are expected to reach 47,600,000 by 2018 (Navigant Research, 2013).

Bike-sharing systems (BSSs) have been expanding even at a higher rate over the past fifteen years, especially in European and East Asian countries (DeMaio, 2009). According to late United Nations data, both the number of countries with at least one BSS, the total number of BSSs, and the total number of bikes used in BSSs have dramatically increased from 2000 to 2013 (Midgley, 2011). It has been estimated that in December 2016 there were over 1,100 fully automated active BSSs around the world, with 2,294,600 bicycles and more than 10,000 e-bikes (Metrobike, 2017). In 2016 BSS bikes are reported to be more than five hundred and fifty times those used in 2000 (Figure 1).

The literature on BSS development agrees on dividing it in four 'generations' (Table 1). Everything started with the pioneering project of the 'white bikes' in Amsterdam in 1964-65, when the local city council decided to implement a free-of-charge BSS. Amsterdam residents and in general all the Netherlands have a long tradition in the use of the bicycle as a mean of small-range transportation. However, the program was not envisaged as a real self-sustainable system leading to a real city transport service, and, most importantly, was not supported by an adequate technology. Therefore it collapsed shortly (Tironi, 2015).

After a while, a second generation of BSS was launched in Denmark (like the Netherlands, this is a country with a strong cycling tradition). A small deposit system was introduced to unlock bikes, and for the first time a network of automated docking stations was 


\section{ACCEPTED MANUSCRIPT}

introduced (DeMaio, 2003). An important change was introduced in the late nineties, when hightech IT BSSs were introduced: smart and stripe cards for subscription and payment were used for the first time in Rennes (France) in 1998. From the marketing side, a wider offer of different subscriptions was implemented, in general with costs increasing with the usage. This was called the 'BSS third generation', the first one to survive vandalism and theft, and to be selfsustainable. Keys for the BSS's success in this period were the new three-party business model (the municipality proposing the service, the company running the service and the bike users, each of which benefiting from this structure), and the new large-scale service system (with hundreds or even thousands of bikes for each BSS). The most important BSS example in this generation is that of Lyon (France). The last (fourth) generation started around 2007 and was characterized by the development of numerous BSSs even in smaller towns, with a huge injection of smart hightech tools in the system. The most notorious example is the BSS in Paris in 2007. Bicycles equipped with locking pins with unique-code identifier chips, docking stations connected via radio antennas and/or wi-fi, IT infrastructure for data processing (a useful innovation for successfully managing the logistics for the system functioning) and, finally, web-based 'virtual stores' for bike accessories requiring the use of credit cards were gradually introduced. The introduction of electronic bikes is now considered the new challenge.

In the fourth generation a real boom of BSSs all over the world has been experienced. For example in France, almost all the municipalities with more than 100,000 inhabitants adopted a BSS by 2014. Most of the development of the French BBSs was concentrated in the eight/nine years of the fourth generation (Figure 2). 


\section{ACCEPTED MANUSCRIPT}

This spread has attracted researchers' attention, and therefore the literature related to bike sharing has also seen a steady growth. Figure 3 shows the constant increase in the number of published papers on BSS topics from 2010 to 2015, according to yearly-based queries on Google Scholar using the search term "bike sharing".

\subsection{Issues around satisfaction with public sector services}

The evaluation of satisfaction for privately produced goods can be deeply different from that regarding public services. Private companies have the right expertise to monitor the satisfaction with their products almost in real-time: a simple increase in sale volumes, a good reception of advertising policies or the level of participation to games/lotteries/loyalty schemes accompanying product sales can be sufficient means for evaluating the satisfaction among consumers. On the contrary, an enterprise providing a public service and operating in a monopoly might well be unaware of the lack of satisfaction among its users if there is no opportunity to switch to other providers, refuse or reduce the service. Moreover, results of new sale policies can have a larger horizon, and the provision of public services can strictly be linked to politics and other related fields, like taxation, public expenditure and public monetary policy (Ferrari \& Manzi, 2014).

Satisfaction/opinion surveys on public services are therefore affected by specific sources of bias: respondents might feel less comfortable and at ease in revealing their opinion on delicate public topics like crime, police, prison and health service (Van Ryzin \& Charbonneau, 2010). As a matter of fact, respondents may have a negative attitude towards public services and have an interest to under-report their satisfaction, due to a 'not-in-my-backyard' mentality, or have an incentive to 'strategically' misrepresent their preferences in opinion surveys, with the aim of 


\section{ACCEPTED MANUSCRIPT}

influencing policy decisions or favour their political side (Ansolabehere \& Konisky, 2009; Wardman, 1988). Van de Walle \& Van Ryzin (2011), using a split-ballot experiment, found that even the simple order of questions in a survey on satisfaction with public services can have important effects on reported satisfaction, resulting in different levels of overall satisfaction as far as the order of questions is changed. This fact has important consequences when conducting and analysing satisfaction surveys on public services, and therefore more care and variety of analytical tools must be used for sensitive and confirmation analysis to avoid distortion and bias. Moreover, unobserved variables may deeply affect users' perception of a public service. For example, Chica-Olmo et al. (2017) in a satisfaction analysis of a public transport system in Granada, Spain, found that these unobserved variables may be related to service management, vehicle commercial speed, type of journey and waiting times. Sometimes there could be also an amplification effect, i.e. satisfaction can result higher simply because some features of the service are unusual in the public sector. High-tech innovations introduced in the provision of a public service can be felt more positively than in the private sector where usually they are considered normal.

\subsection{Satisfaction for BSSS}

Innovation is crucial for the functioning of a public service, but in terms of satisfaction results are astonishing if innovation is introduced. This is the case of the BSSs. The steady growth of urban population combined with the increase of car traffic volumes, environmental pollution and fuel prices have driven urban developers and city councillors to experiment new systems for a sustainable mobility. But the crucial innovation which overwhelmingly contributed to the boost of the fourth BSS generation was the introduction of mobile phone-based technology 


\section{ACCEPTED MANUSCRIPT}

to book, pick, lock and pay for the bikes. Mobile technology has changed the consumer's attitude in transportation mode and mobility behaviour. Scenarios on a smart use of increasingly available information about traffic on travel routes, and learning data technologies suggesting best practices in using combined means of transportation are now in the 'Technopolis' futurist vision of ecologic development, to use a fortunate definition by Sale (2011). Thanks to mobile technologies BSSs are today, together with other alternative mobility sharing systems like car sharing, a fundamental component of the modern 'smart city' and is having important positive implications on the level of employment, public and private investments and citizen approval. BSS providers may analyse a huge amount of data concerning the management of the service almost in real-time on the basis of users' usage and behaviour.

To sum up, and for the reasons above outlined, the actual quality of a given public service results in most cases underrated among its users. In less frequent cases it results overrated when popular technologies are adopted for the completion of the service. The latter could be the case for the BikeMi BSS service in Milan, Italy. A survey performed in 2014 resulted in a very high overall satisfaction with this service. Characteristics of this survey will be described in detail in Section 4, and its data will be used for the satisfaction analysis in Section 6.

There has been an increasing number of analyses concerning the perceived quality of BSSs

(see for example, among recent analyses, Kim et al. (2017b) on the perception of the value of public bike system with reference to individual's psychological variables, especially concern about the environment, and Munkácsy \& Monzón (2017) for a detailed identification of the characteristics of Madrid's BiciMAD BSS users). These studies are often performed following multiple lines of research, from bike journey analysis to comparison with car-sharing system, 


\section{ACCEPTED MANUSCRIPT}

often focusing on the relationships with existing transportation infrastructure and the impact on air pollution, and are based on data resulting from focus groups, telephone interviews, face-toface interviews or web surveys, often based on general mailing lists of citizens or active users of BSSs. These studies may be enhanced with analyses on bike journeys, which can be compared with analyses on car owners, existing transportation infrastructures and air pollution.

The aim of this paper is to investigate whether the overall high satisfaction resulting from the BikeMi opinion survey is justified, or whether there are some hidden issues not immediately detectable by an analysis performed on the surface. To do this some statistical techniques will be used to both construct composite satisfaction indicators and to detect components of the service lacking satisfaction. Another aim is to check whether these techniques bring to similar conclusions regarding the level of satisfaction, in a sort of 'satisfaction sensitivity analysis'. The paper is therefore organized as follows. The next section will briefly present a summary of the literature on the BSS customer satisfaction, and section 3 will outline the most important characteristics of the BikeMi BSS in Milan. Section 4 will contain a short description of the survey, some features of the resulting data set and some exploratory analysis on this data, presenting descriptive statistics on single items of the questionnaire. Section 5 will present the theoretical aspects underlying the construction of the satisfaction indicators used in Section 6, where also the core results of this satisfaction analysis will be presented and a validating textual analysis of the responses to the open question included in the questionnaire will be also presented. Section 7 will conclude the paper with a thoughtful discussion about the main results of this research, together with a sketch of possible future developments.

\section{A short literature review on BSS satisfaction research}




\section{ACCEPTED MANUSCRIPT}

Satisfaction is a psychological phenomenon, resulting from personal emotional states, influenced by factors internal and external to the individual (Locke, 1967), and subject to a considerable variability among individuals. For these reasons its measurement has always been at the centre of the literature focusing on satisfaction with public services. The most important methodological point addressed by researchers is the scale used to ask people questions about the evaluation of satisfaction. One of the most used scales in opinion surveys is the Likert scale (Likert, 1932): it can ease and speed up the analysis, but it can also be interpreted very differently from respondent to respondent (Ferrari \& Manzi, 2014; Cheng and Liu, 2012; Harwell \& Gatti, 2001). The Likert scale should therefore be used together with other statistical methods apt to unveil respondents' hidden behaviour in answering questionnaire items and discover nonlinearity from one level of the scale to another.

In general, shared public transportation systems (mainly bike and car sharing systems) have become a 'hot topic' in transportation literature, given that they are widely considered a solution for solving traffic problems in modern congested cities. A huge number of researchers have devoted their research to these phenomena (see, for example, Richardson et al. (1995) on performing adequate surveys on public transportation; Shaheen \& Guzman (2011) on the status of art of worldwide bike sharing; Murphy \& Usher (2015) for an analysis of bike sharing usage in Ireland; Ji et al. (2014) who describe the operational concepts and system requirements of a fully automated e-bike sharing system at the University of Tennessee; García-Palomares et al. (2012) on the optimal allocation of docking stations using GPS systems and Caggiani \& Ottomanelli (2013) on optimal bike fleet repositioning), even if there is a large methodological variation among all such research, especially when attempting to unfold the determinants of the 


\section{ACCEPTED MANUSCRIPT}

BSS success/failure. Other authors encompassing this field usually refer to the impact on car ownership and usage in large cities when city planners make restrictive changes in this direction while promoting and implementing BSSs (Krizek \& Stonebraker, 2011).

Another important issue addressed in the growing body of public transportation is the target of the customer satisfaction analysis (Kim et al., 2017a). According to some authors, the content of the interview and the purpose for which data are collected are key factors for a successful analysis. Often the purpose of these analyses lies in careful planning and implementing new business policies in order to better respond to users' needs. In some cases surveys not only aim at measuring customer satisfaction, but also at investigating additional aspects: the implementation of policies to facilitate the diffusion of these mobility systems as well as the alternation between private car ownership, existing transportation infrastructure and BSSs (Shaheen et al., 2010). While such surveys have been often developed with classical survey methods or through convenience survey methods (for example, with respondents selected directly nearby the bike docking stations), focus groups methods asking participants for open responses conveying their opinions or feelings about the service are gradually gaining momentum (Bachand-Marleau et al., 2012).

BSSs have been analysed in many countries. Research concerning user satisfaction for BSSs includes analyses carried out in Canada (Bachand-Marleau et al., 2012; El-Assi et al., 2015), the United States (Shaheen \& Guzman, 2011), Australia (Fishman et al., 2014) and the United Kingdom (Kingham et al., 2001). The China case is analysed by Shaheen et al. (2011) and, for the case of the world's biggest BSS in Hangzhou, by Zhang et al. (2015a). One shared feature of these studies is that they are presented as a result of a research project proposed to and 


\section{ACCEPTED MANUSCRIPT}

conducted in partnership with the institutions owning and managing the BSSs, being seldom conducted independently (see also Kingham et al., 2001; Grigoroudis \& Siskos, 2004). However, some exceptions exist like the study presented in Nikitas et al. (2016), where an analysis about public attitudes towards the bike-sharing scheme in Gothenburg, Sweden, is conducted independently from institutions owning and managing the local BSS. Some studies also highlight the importance of running BSSs under the umbrella of non-profit organisations (NPOs). Nakamura \& Abe (2014) showed that NPOs could be successful in situations where the scale of BSSs is relatively small and securing funding and appointing operators could turn out to be difficult.

With the exceptions outlined above, analyses carried out by researchers in this area share three common characteristics: (i) they take information from representative samples and almost never from the whole population of users; (ii) these surveys are seldom realized as independent projects from the BSSs operators, (iii) users have often been found through focus groups or telephone surveys and sometimes with the use of online surveys - never through a complete list of users who are certainly active in the usage of the service.

\section{The BikeMi BSS}

BSSs' success depends on many variables, among others the characteristics of the territory, the state of the roads, the development of cycle lanes, the car traffic intensity, the economy of the area and the general transport system where they are deployed. The city of Milan is located in the flat northern Italian region of Lombardy immediately South of the Alps, and is the most important industrialized city of Italy. It is quite a polluted town, but some environmental measures aiming at contrasting the pollution have been introduced recently. A congestion charge 
for an area of $181 \mathrm{~km}^{2}$ in the city centre was introduced in 2008 and an extension of the area of this congestion charge in 2012.

The public transport system includes four subway lines (one of which is with the automatic train operation system) with a total network length of $96.8 \mathrm{~km}$ and 113 stations, 98 bus lines with a total network length of $845 \mathrm{~km}$ and 1,378 vehicles, 20 streetcar lines with a total network length of $180.4 \mathrm{~km}, 481$ vehicles, and 4 trolleybus lines ${ }^{2}$. There are three major terminal railway stations in the metropolitan area with an average passenger flow of more than 25,000 passengers per working day ${ }^{3}$, and a network of 12 suburban train lines. Regarding car-sharing services in 2017 the number of shared vehicles was about 2,400, with an average of about 12,750 rentals per day $^{4}$.

Common features of modern BSSs are (ITDP, 2014): (i) a shared pick-up mode with easy-toaccess docking stations conveniently distributed in the urban area; (ii) bicycles with specially designed parts and sizes that discourage theft and resale; (iii) wireless systems for real time

${ }^{2}$ These are 2015 data taken from the ATM website (http://www.atm.it/it/IlGruppo/ChiSiamo/Pagine/Numeri.aspx, accessed on April 29 ${ }^{\text {th }}, 2017$, in Italian). ATM is a public company operating the underground and bus transport services in Milan.

3 Milan's main railway station, 'Milano Centrale' counts about 320,000 passengers per day (http://www.grandistazioni.it/cms/v/index.jsp?vgnextoid=aaf5d92b909ea110VgnVCM1000003f16f90aR $\underline{\mathrm{CRD}}$, accessed on April 29 ${ }^{\text {th }}, 2017$, in Italian). No recent data about passengers' flow are available for the other two major railway stations, 'Milano Porta Garibaldi', and 'Milano Cadorna', but Milano Porta Garibaldi is classified as a 'platinum station' (i.e. a station with more than 25,000 passengers per day) by RFI, the company operating the railway infrastructure service in Italy (http://www.rfi.it/rfi/LINEESTAZIONI-TERRITORIO/Le-stazioni/Vivibilità-e-fruibilità/La-classificazione-delle-stazioni-ferroviarie, accessed on April 29 ${ }^{\text {th }}, 2017$, in Italian), whereas for Milano Cadorna (operated by the LeNord company) it could be inferred a similar or even larger flow since for only one among the many train lines ending in Milano Cadorna (the line 'Varese-Milano Cadorna') it is estimated a flow of 39,000 passengers per working day (http://www.varesenews.it/2017/03/trenord-numeri-ritardi-passeggeri-orari/607330/, accessed on April 29 $9^{\text {th }}, 2017$, in Italian).

${ }^{4}$ These data were presented by Urbi, a company producing a mobile application for real-time access and information about the car-sharing system in Milan, at the Second Workshop "Smart Mobility in Smart City", March 14th, 2017, University of Milan (http://milano.repubblica.it/cronaca/2017/03/14/news/milano_car_sharing-160537165/, in Italian, accessed on April 29th, 2017). 


\section{ACCEPTED MANUSCRIPT}

monitoring of station occupancy; (iv) real-time user information systems through various platforms, including the web, smart phones and on-site terminals (v) pricing structures that incentivize short trips helping to maximize the number of trips per bicycle per day, often with free-of-charge initial time of use; (vi) an unrestricted usage in terms of origin and destination; (vii) penalties imposed for misuse. However, there are also differences. For example, the business models chosen to manage the service differ from context to context, ranging from completely public to completely private systems, with public-private mixed forms largely more popular. Involved operators include local governments, public transport agencies, advertising companies, and for-profit and non-profit groups (Midgley, 2011; Shaheen et al., 2010). BSSs can or cannot be integrated with bus and underground public transport systems. The success of a BSS depends on many variables, but these variables change over time, so that a continuous monitoring is needed (Lathia et al., 2012).

BikeMi in Milan is no exception, being the biggest and most innovative BSS in Italy and presenting many specificities and differences with other BSSs. BikeMi started in November 2008 and was the first Italian privately managed bike shared system. Presently 3,300 bikes are distributed across 192 stations over a $13 \mathrm{Km}^{2}$ urban area centred in the "Duomo" main square (Figure 4).

A credit card is required to sign in to the service ${ }^{5}$. A call center and an official website are available to customers. Prices for membership are by renting duration: 4.5 Euros for a daily subscription, 9 Euros for the week subscription and 36 Euros for a whole year. The BikeMi card is issued for free, but its re-issuing cost is 5 Euros. The first 30 -minute usage is free for the

\footnotetext{
${ }^{5}$ Subscription fees presented here are those of 2017.
} 


\section{ACCEPTED MANUSCRIPT}

standard bike (a common policy for BSSs) and is 0.25 Euros for e-bikes, with a subsequent fare increase based on blocks of 30-minute increments. Subscription is suspended after 3 missed returns with a maximum fine of 150 Euros.

From 2009 to 2012, both the number of stations (part (a) in Figure 5) and the average number of daily journeys (part (b) in Figure 5) considerably increased, the former from around 110 to around 160 , the latter from almost 2000 to almost 4000. During traffic congestion and events like public transportation strikes or political rallies the number of daily journeys usually doubles ${ }^{6}$.

During peak periods the bike traffic converges more intensively towards docking stations situated in central areas. Peak-period traffic has increased more than other day periods during the years. Similarly to other BSSs, three peaks periods can be discerned. The first one is at 8AM (with more than 56,000 overall journeys recorded in October 2016), the second one at 1PM (with more than 26,000 journeys) and the third one at 6PM (with almost 33,000 journeys). On average, in 2016 each bicycle was used more than four times per day, whereas it was used only once per day in 2010. In terms of usage intensity the most important stations are those in the very city centre where pedestrian areas are located. Other important locations are those near the main railway stations.

So far, the BikeMi scheme and its impact on citizens have not been studied in depth. Saibene \& Manzi $(2014 ; 2015)$ have reported on the BikeMi expansion from its beginning and on the determinants of the BikeMi usage. Croci \& Rossi (2014) have performed a study on the docking station optimal positioning. To our knowledge no other major research has been

\footnotetext{
${ }^{6}$ Data on BikeMi traffic are provided by Clear Channel Italy, the company in charge of the service.
} 


\section{ACCEPTED MANUSCRIPT}

conducted about BikeMi. Therefore there exist a certain research gap on this BSS, which this paper aims at filling.

\section{Survey characteristics, data collection and exploratory analysis}

The web-survey that originated the data for this study was commissioned by the company operating the BikeMi BSS, Clear Channel Italy, and was designed and distributed by the authors who also did the first analysis. It was conducted from the beginning of March 2014 to the end of May 2014. Current subscribers of BikeMi formed the target population. All subscribers were contacted through the email addresses they gave in the registration form at the time of their subscription. Two recalls were necessary after the initial contact to obtain a final response rate of $47.6 \%$ for a total of 10,055 respondents over more than 21,000 BikeMi users. The final composition in terms of demographic and socioeconomic characteristics of the responding subscribers resulted very similar to the composition of the whole population of subscribers.

The questionnaire consisted of 26 questions subdivided in three sections (section A with 7 items regarding personal data and demographic information, section B focusing on satisfaction with the service with 8 items, and section $\mathrm{C}$ asking motivations and ways of using the service with 11 items). All responses to questions concerning opinion on satisfaction were on a 5-level Likert scale ranging from 'very dissatisfied' to 'very satisfied', with 'neither satisfied nor dissatisfied' being the middle point category. There was an additional open question having the purpose of collecting suggestions from respondents, and two further binary questions regarding the possibility of introducing electric bikes. The complete questionnaire, made of four dichotomous questions (affirmative-negative and the gender question) eight Likert scale questions, thirteen multiple choice questions and one open question is reported in a translated 


\section{ACCEPTED MANUSCRIPT}

version from the original Italian version in Appendix 1.

The average profile of a BikeMi user resulted from the survey was a 41-year-old, male professional, who uses the BikeMi bicycle to go to work for the last mile of his daily commuting journey. $61.6 \%$ of the respondents were men, whereas $38.4 \%$ women (Figure 6a). Male users' average age was 42 years, whereas female users' average age was 38 years. The majority of respondents $(49.4 \%)$ were managers, self-employed or consultants/entrepreneurs. Students were $5.7 \%$ of the respondents, whereas pensioners only $2.8 \%$ (Figure $6 \mathrm{~b})^{7}$. The service attracted a high percentage of commuters (more than 25\%) outside the Milan metropolitan area (Figure 6c).

Overall, people aged 30-49 years were the most numerous (57.2\%). Young people were in the minority ( $15.0 \%$ between 20 and 29 years, and only $0.8 \%$ under 20 years), while those aged 50 years or more were $27.0 \%$ (Figure $6 \mathrm{~d}$ ).

The level of education among respondents was considerably high. The BikeMi average user has at least a three-year university degree. Some 7,500 respondents (74.3\%) said they have a three- or a four-year university degree, a master degree or a $\mathrm{PhD}$. Only about 2,500 respondents (24.1\%) said they have a secondary school degree (Figure 7a). Among survey respondents there were more unmarried than married people, even if the difference resulted slightly noticeable: about 4,700 (46.5\%) versus about 4,600 (45.4\%) (Figure 7b).

The question about the fairness of the subscription fares (question Q8) received largely positive results (Figure 8a), despite the fact that in marketing surveys it is usually not easy to find favourable responses to this type of questions. For example, for the case of a survey carried out

\footnotetext{
${ }^{7}$ These low percentages for students and pensioners can be explained from the fact that youngsters and elders in Italy do not hugely use credit cards. Pulina (2011) examined 320,000 Italian data on credit cards collected from recent bankcard account archives for an Italian based issuer. Only $3.2 \%$ and $6.7 \%$ of credit cards were issued to customers aged 18-25 years and 66-75 years, respectively.
} 


\section{ACCEPTED MANUSCRIPT}

in the same period of the BikeMi survey, Munkácsy \& Monzón (2017) reported a somewhat negative evaluation of the tariff scheme adopted by the BiciMAD BSS in Madrid, Spain, especially for per-use tariffs and for occasional subscriptions.

Strategic questions for the launch of the first integrated electric bike sharing on a large scale in Europe have also been placed in the questionnaire. Since May 2015 the BikeMi service offers the opportunity to rent electric bicycles equipped with GPS. Respondents declared to be interested in the introduction of such type of innovations with a positive response in $70 \%$ of the cases (question Q24). This is quite an opposite result compared to that obtained in the aforementioned BiciMAD survey where people mainly declared that they were not familiar with e-bikes and therefore did not appreciate the fact that all the BiciMAD bikes will be e-bikes (Munkácsy \& Monzón, 2017). Respondents declared to be willing to pay a premium cost to use a more comprehensive service in 35\% of cases (Question Q25). Thus, it can be said that a large number of users nurtures positive expectations and approve innovative improvements. Therefore, these responses are in line with the general consumer's behaviour literature for which if an added value can be obtained from the product/service offered (that is, either it is scarce, or specific consumer's purpose-driven behaviour is present, or products provide quality and value superior to the fair price, or, finally, benefit for the consumers is combined with a cause) the consumers will have a willingness-to-pay-more attitude (Goldsmith, 2015; Vlosky et al., 1999; Rao \& Bergen, 1992; Bischoff, 2014). A slightly lower appreciation was shown for the comfort of the bikes (question Q9): only about 37\% of the respondents declared that they feel comfortable using the bikes (Figure 8b). The customer care service (question Q10) was very much appreciated by users $(62 \%$ responded positively or very positively - Figure $8 \mathrm{c})$. Bike stations were found well 


\section{ACCEPTED MANUSCRIPT}

located in the city centre (question Q11 - Figure 8d), while the system for renting a bike (question Q12) was highly rated among $72 \%$ of the respondents (Figure 8e). The worst evaluation seems to be the one on the quality of the bikes (question Q13 - Figure 8f): only about $25 \%$ of respondents declared that the bikes operate well. Finally, respondents thought that the BikeMi service is an effective alternative to the private car (question Q14) in more than $82 \%$ of the cases (Figure 8g). Overall, BikeMi users were satisfied (55\%) or extremely satisfied (16\%) with the service (Figure 9).

More than $51 \%$ of respondents said that they use BikeMi to travel to their workplace (Question Q16 - Figure 10a). The distance travelled by users usually ranges between two and four kilometres (nearly $50 \%$ of respondents - Question Q17, Figure 10b). The time of use most often is found to be between 10 and 30 minutes (almost $60 \%$ of respondents - Question Q18, Figure $10 \mathrm{c}$ ). Nearly $30 \%$ of respondents said they use the service BikeMi daily, while $17.6 \%$ say

they use it on weekdays. Regarding the transport service most integrated with the BSS (Question Q21), the underground was ranked first (58.7\%), followed by the bus (38\%), the car (28.8\%) and the rail $(22.1 \%)$.

In Table 2 descriptive statistics on the satisfaction with seven aspects of the service and the overall satisfaction (corresponding to questions Q8-Q15 in the satisfaction section of the questionnaire) are reported. It can be noted that both the mode and the median are lower for the two responses regarding the evaluation of the bikes' component (bike comfort and handling (Q9): median=3, mode=3; bike quality and functioning (Q13): median=3, mode=3), for which also a slightly negative or a positive skewness is present (the skewness coefficients are -0.169 and 0.037 , respectively). Highest ratings are achieved for subscription fee (Q8: median=5, 


\section{ACCEPTED MANUSCRIPT}

mode $=5)$ and for evaluating the BikeMi service as a valid alternative to the private car $(\mathrm{Q} 14$ : median $=5$, mode $=5)$, for which high negative skewness coefficients are reported $(-1.392$ and 1.344 respectively). More variable opinions are present for bike comfort and handling and for the evaluation of the automatic renting system (the interquartile range is 2 in both cases). The interquartile ranges of the other questions are all equal to 1 . There is a huge concordance in a positive overall evaluation of the service (question Q15): both the median and the mode are equal to 4 and the interquartile range is 1 . From this analysis, bike components and comfort can be considered as initial 'candidates' to be slightly less successful than other components of satisfaction. In the next sections this hypothesis will be tested with a more detailed analysis.

Finally, in Table 3 a correlation matrix concerning the eight satisfaction variables is presented. Coefficients are positive and range from 0.132 (between the variables bike quality and functioning - Q13 - and BikeMi as a valid alternative to private car - Q14) to 0.521 (between the variables bike quality and functioning - Q13 - and bike comfort and handling - Q9). As for the overall satisfaction, the highest correlation is with the variable bike comfort and handling (0.503), whereas the lowest is with the variable subscription fee reasonability $(0.382)$.

\section{Statistical tools for satisfaction analysis}

In this section the main features of the statistical technique used in the satisfaction analysis are presented. The presentation of this technique is not exhaustive, but is aimed at outlying the core parts and the particular aspects of them which are useful to better clarify our analysis.

Nonlinear Principal Components Analysis (NLPCA) is the natural extension of Principal Components Analysis (PCA) to categorical/ordinal data (Michailidis \& De Leeuw, 1998). As PCA, NLPCA aims at reducing dimensionality of the data from an $m$-dimensional to a $p$ - 


\section{ACCEPTED MANUSCRIPT}

dimensional space (normally, $p<m$ ). One important additional feature of NLPCA with respect to PCA is to obtain optimal quantifications of the original categories of the variables, according to the following minimization problem for a loss function $\sigma$ :

$$
\sigma=\frac{1}{m} \sum_{j=1}^{m} \operatorname{tr}\left(\boldsymbol{X}-\boldsymbol{G}_{j} \boldsymbol{q}_{j} \boldsymbol{\beta}_{j}^{T}\right)^{T}\left(\boldsymbol{X}-\boldsymbol{G}_{j} \boldsymbol{q}_{j} \boldsymbol{\beta}_{j}^{T}\right)=m^{-1} \sum_{j=1}^{m}\left\|\boldsymbol{X}-\boldsymbol{G}_{j} \boldsymbol{q}_{j} \boldsymbol{\beta}_{j}^{T}\right\|^{2},
$$

where $m$ is the number of variables, $\boldsymbol{G}_{j}$ is a $n \times k_{j}$ indicator matrix (with $n$ being the number of respondents and $k_{j}$ the number of categories for variable $\left.j, j=1, \ldots, n\right)$ indicating the presence of categories for variable $j, \boldsymbol{q}_{j}$ is a $k_{j}$-dimensional vector of optimal category quantifications for variable $j, \boldsymbol{\beta}_{j}$ is a $p$-dimensional column vector of component loadings ( $p$ is the number of extracted components), and $\mathbf{X}$ is a $n \times p$ matrix of scores representing the respondents in a new coordinate system with new components representing hidden traits, like in PCA. Solutions are found by using an Alternating Least Squares iterative algorithm with the following restrictions aiming at avoiding trivial solutions:

$$
\boldsymbol{u}_{n}^{T} \boldsymbol{X}=\mathbf{0},
$$

and

$$
\boldsymbol{X}^{T} \boldsymbol{X}=n \boldsymbol{I}
$$

where $\boldsymbol{u}_{n}^{T}$ is a vector of ones of order $n$, and $\boldsymbol{I}$ is the identity matrix. The solution for obtaining optimal quantifications pertains to the optimal scaling families of algorithms.

In the case of ordinal variables like those using a Likert scale, optimal quantifications of categories from a NPCA account for the nonlinearity possibly existing between them (Manisera et al., 2010). This means that the 'distance' between, say, response 1 and response 2 to a particular question could in reality be different from the 'distance' between 2 and 3, depending 


\section{ACCEPTED MANUSCRIPT}

on how globally respondents have treated that question. This has important consequences in terms of revealing hidden structures in the data. First of all, by construction the quantifications are found such that the overall variance accounted for in the transformed variables is maximized, an important principle at the basis of PCA. Secondly, quantifications of variables can reveal hidden behaviours of respondents to a questionnaire, aside from an apparent result immediately observable from a descriptive analysis. Especially in public service opinion surveys, selfreported expressed opinions can be affected by how the respondents feel more or less comfortable with a particular question or with the survey in general, especially when one feels to be in the minority (Ferrari \& Manzi, 2014; Ho et al., 2013; Noelle-Neumann, 1974).

In Subsection 6.1 some ingredients of NLPCA from (1) will be used in order to analyse the BikeMi survey data. First, component loadings produced by NLPCA are considered. They can be interpreted as the correlations between the original variables and these new components, in order to characterize the components as separate features of satisfaction. Then, the simple satisfaction indicator proposed by Ferrari et al. (2010) will be used to compare the satisfaction within multiple groups of respondents, which is based on a group average of scores produced by a NLPCA once a variable is chosen to form the groups. Finally, adjusted averages of quantifications will be computed to take account of the presumed nonlinearity in the ordinal values of the satisfaction variables.

\section{Satisfaction analysis}

In this Section the tools described in Section 5 are used to perform an analysis on the data from the satisfaction part of the survey. The potentiality for using these tools to build up synthetic satisfaction indicators is ascertained, and a presentation of the results in comparative terms is 


\section{ACCEPTED MANUSCRIPT}

outlined. A simple confirmative textual analysis using the open question about the service will be performed in Subsection 6.2.

\subsection{NLPCA results}

The first step of our NLPCA analysis was to find the number of components to be extracted when performing a NLPCA on the satisfaction variables (questions from Q8 to Q14 in the questionnaire, excluding the general question Q15) ${ }^{8}$. This is an important task, since it is aimed at retaining as much information from the original variables. Therefore, the 'eigenvalue greater than one' criterion and the scree test were used (Cattell, 1966; Jolliffe, 2002; Kaiser, 1960 - see Table 4 where also Cronbach's $\alpha$ values are shown for each component ${ }^{9}$, and Figure 11 where the scree plot is displayed).

According to the aforementioned criteria, the number of components to be extracted is the last one having the eigenvalue greater than 1, or a positive value of the Cronbach's $\alpha$. This is enhanced also by the scree plot, where the components appearing before the 'break' (that is, the point from which the slopes of the lines joining two successive points start to level off) should be considered meaningful for the analysis. From this check it is clear that two components should be extracted from our set of seven satisfaction variables. Therefore, a NLPCA with two extracted components was performed, for which similar values for the variance accounted were obtained (the first eigenvalue was 2.716 and the second one was 1.117).

A correct interpretation of the components as the latent satisfaction traits underlying the

\footnotetext{
${ }^{8}$ This analysis was performed using CATPCA in IBM SPSS 23.0.

${ }^{9}$ Cronbach's $\alpha$ is in general a measure of reliability and internal consistency, that is how much a group of items can be considered closely related; in NLPCA it has a direct relationship with the corresponding eigenvalue: $\alpha=M(\lambda-1) /(M-1) \lambda$ (Heiser \& Meulman, 1994).
} 


\section{ACCEPTED MANUSCRIPT}

observed satisfaction variables is important for a successful satisfaction analysis. Therefore, an analysis of the component loadings (which basically give the correlations between the new components and the original variables) was necessary: the more an original variable is either strongly positively or negatively correlated with a component, the more it is a 'constituent' of the new component. From the component loadings displayed in Table $5^{10}$, it can be argued that the first component is highly positively correlated with variables Q9 and Q13, which are concerned with the comfort, functioning and reliability of the bikes.

The second component is highly positively correlated with variables Q8, Q11 and Q14, which can be viewed as more general evaluations of the service, since they are mainly related to overall aspects of BikeMi. In the following, this component will be denoted as 'General aspects of BikeMi'. More controversial seems to be the assignment of variables Q10 and Q12 to either the first or the second component. Here another residual component encompassing these two variables could have been considered, but in general such a small number of variables with high loadings are considered too few to form a separate component (Stevens, 1992). On the other hand, the customer care service and its call center are much more related with the everyday life of the service: most probably, customers' calls are complaints about technical problems in some way related to the bikes. Similarly, the renting and the picking system can be referred as being part of the technical aspects of the service. Therefore, we decided to assign both variables to the first component (see the loadings in bold in Table 5). In what follows, this component will be denoted as 'Everyday technical aspects of BikeMi'.

\footnotetext{
${ }^{10}$ To have a better understanding of the components, a varimax rotation of the components is normally suggested (see, for example, Kaiser, 1958). Therefore, in Table 5 the rotated component loadings are reported.
} 


\section{ACCEPTED MANUSCRIPT}

After the selection of the components we concentrated on one of the outputs of NLPCA, the object scores. In this subsection the results from this analysis are presented. A simple indicator proposed by Ferrari et al. (2010) is used to compare multiple groups of respondents, which in this case is based on a conditional mean of object scores produced by a NLPCA with two extracted components. For each group $\gamma$, let $\overline{\boldsymbol{x}}_{\gamma}$ be this conditional mean, which is a twodimensional vector formed by the means of the scores of the first and the second component. Then, for each element of this vector, values greater than zero denote a satisfaction greater than the average satisfaction among all the respondents within group $\gamma$.

In Table 6 these conditional means of scores are reported for some of the demographic questions included in the questionnaire. Women are less content than men both for general and everyday technical aspects of the service, with a huge gap for the former. This is due mainly to the weight and functioning of the bikes, which are considered heavy and difficult to handle when picking and dropping them from/to the locks by female cyclists. This and similar results were confirmed by the textual analysis we performed on the open question Q25 of the questionnaire (see Section 6.2). With regard to everyday technical aspects, the youths and the elders are less satisfied than middle-aged users, and so are the less educated users. Managers are the most satisfied group for the everyday technical aspects among all the job status groups considered. Married users are more satisfied than unmarried users.

Regarding the general aspects of the service, satisfaction evaluations are reversed for the age groups: younger and older people are more satisfied than middle-aged people. This result could be explained by the fact that middle-aged people use the bike mainly for commuting to their working sites, especially during rush hours, and for this reason they find the bike in general 


\section{ACCEPTED MANUSCRIPT}

and the BikeMi bike in particular particularly slow. Furthermore, they find the distribution of the docking stations in the city not highly functional to their purposes. Middle-aged people are also the majority of the users of car-sharing systems, and therefore they tend to compare BSSs to carsharing system in terms of efficiency and speed to reach their working destinations. This result is consistent with the cluster analysis results in Munkácsy \& Monzón (2017), where students and inactive people were identified among the "fans" of the Madrid BSS, and with the factor analysis in Kim et al. (2015), where age was found as a significant positive determinant of electric vehicle sharing program satisfaction in a sample where there were no respondents aged less than 20 years and respondents aged more than 59 years were only $0.2 \%$. People having a tertiary degree are again more satisfied than less educated people (this is mainly due to the high percentage of positive responses to the Q14 question in the group of people having a high-level degree who in general are more sensitive to ecological issues than less educated people), whereas managers, self-employed workers and students are the most satisfied groups. Married users are again more satisfied than unmarried users.

In sum, it seems that the physical structure of the bike is a discriminant factor penalizing the less able to cope with the difficulties of cycling - i.e. women, elders, etc. - and those who use the service less frequently - i.e. employees and workers, retired people, etc.

Groups formed by the usage variables were also considered. Results of the NLPCA analysis are presented in Table 7. Users going to school/university, work and shopping are more satisfied than people using BikeMi for a leisure journey in the city: again, here the heavy and not handy structure of the bike does not help. BikeMi is good for those using it for short distances or short time. A high level of dissatisfaction is recorded for those using the service for long 


\section{ACCEPTED MANUSCRIPT}

distances and for a long period of time. Those using the service almost everyday are satisfied the most, whereas those almost never using it are among the most dissatisfied users. There seems to be more satisfaction among those using the service not in connection with other transport services. The bike enthusiasts are of course among the more satisfied, whereas there is a slight scepticism among those thinking that cycling in town is not good for the health. Among the groups formed by categories of downsides of BikeMi, those in the group of people thinking that the service is 'too slow' are the less satisfied. As for the two questions on e-bikes, those answering 'Yes' to the question 'Would you use the e-bikes' are less satisfied than those answering 'No'. The opposite can be said for the question 'Would you pay more for e-bikes?'.

As a whole, there is quite concordance in the opinions for the two components in almost all the groups. Users definitely will not recommend the service for long journeys, for pleasure, and to use it every now and then.

Table 8 contains averages of the normalized original ratings and averages of the normalized NLPCA quantifications for each question about satisfaction, together with the corresponding grand averages and the overall averages for questions forming the first component ('Everyday technical aspects of the service') and the second component ('General aspects of the service'). The overall normalized average for question Q15 ('Generally speaking, how much are you satisfied with the service?'), which is about a general evaluation of the service and can be considered a term of comparison for our analyses, was 0.702 , which was about $6 \%$ and $2 \%$ more than the grand average of questions Q8-Q14 and the NLPCA overall average, respectively. Therefore, respondents were a bit more positive when responding the general question Q15 on satisfaction. NLPCA quantifications give mixed results, resulting in an overall average greater 


\section{ACCEPTED MANUSCRIPT}

then the simple overall average. However, NLPCA gives overall averages lower than that of the simple average of the original ratings on the everyday technical aspects of the service. In any case, as already stated, since NLPCA was used to test whether there were hidden traits in the response pattern of the respondents, especially 'something to be revealed', not explicitly detectable directly from the answers, the closeness between the results obtained with the three methods means that the respondents actually told the truth about their views, and were not influenced by external factors or by the type of the survey they were involved in.

\subsection{A validating textual analysis}

In this subsection a simple textual analysis on the open question Q26 ('Would you like to leave a comment on the BikeMi service?') is presented. The question was much more intended as a 'suggestion box' to improve the service or express concerns and drawbacks rather than a way to express satisfaction or dissatisfaction, but many people used it to express their feelings about the service. A huge percentage of the respondents (around 37\%) left a comment, sometimes with a very long text. Comments are classified first as opinions about the service or an expression of concern/improvement. Opinion comments were classified simply as 'Good' or 'Bad'. Concern comments were classified with the categories reported in the first column of Table 9. In this table the distribution of the concerns/needed improvements and the opinion about the service are also reported.

Concerns about 'Bike comfort and functioning' (a concern that can be related to questions Q9 and Q13 of the questionnaire) were the most frequent (more than 32\%). 'Picking/dropping system and apps' and 'Station maintenance and bike distribution' (which can be related to question Q12 of the questionnaire) were highly frequent concerns (almost $14 \%$ and $12 \%$, 


\section{ACCEPTED MANUSCRIPT}

respectively). There was a huge concern also for an extension of the docking station network in the city (about $20 \%$ of the respondents leaving a comment) and the opening hours of the service (more than 7\%). There was a lower concern for the customer care service (almost 2\%) and the cost and the form of subscription (less than $1 \%$ and a bit more than $4 \%$, respectively).

The variables in our component 'Everyday technical aspects of the service' were almost always an explicit matter of concern for the users, except for the customer care. The high frequency of 'good' judgments $(88.5 \%)$ confirms that the service is highly rated, but still there are important problems to be tackled. This high rate of positivity when asked to leave a comment confirms some of the hypothesis about the features a (public) service should have in order to be successful, and could be justified with the following three points: (i) in many comments people remark positively the fact that it is possible to find and hire bikes remotely using a smart phone; therefore, as stated in the Introduction, when a service is organized with an innovative and technologically advanced system, people tend to be favourably attracted by it; this is a positive feature from the side of the organization of the system; (ii) many comments are about reducing congestion or pollution for a better mobility in the city centre; this is a positive feature from the side of the possible positive general outputs this system could achieve; (iii) many comments are related to the condition of being a subscriber of the system: for this reason we suspect a slight overestimation of the true level of satisfaction with this service ("I am a subscriber of this service, then I like it"): this is a positive feature from the side of the particular condition of the survey respondents.

\section{Discussion, conclusion and future work}

Sharing mobility has become a valid alternative to car ownership and traditional public transport 


\section{ACCEPTED MANUSCRIPT}

systems in big cities in recent years. Reasons for the increase in the demand for these transport modes are, among others, the constantly growing fuel prices, the increasing congestion in metropolitan areas, the need for green mobility. Together with car-sharing systems, BSSs are increasingly adopted by companies and local authorities in charge of planning new transport schemes. Factors of sharing mobility having a significant positive impact on the urban transport are, among others, the distance among docking stations or car parks, the type of reservation, the type of vehicles, the usage system, the landscape and road network of the urban areas, the user characteristics. For example, Efthymiou et al. (2013) found that the user characteristics prevail on the system characteristics, with car-sharing systems being preferred by bus and tram commuters and bike-sharing by pedestrians.

BSSs in particular have been studied from different points of view in the last years. There is an extensive literature covering different aspects of the service. For example, Kim et al. (2017b) tried to determine which psychological levers to trigger among users to promote sustainable BSSs. Ricci (2015) performed an extensive review of evidence on impacts and processes of BSS implementation and operation. Yang \& Long (2016) analysed the main factors influencing public managers and operators to participate in public BSSs, exploring the case of BSSs in Jiangsu Province, China. Zhang et al. (2015b) studied characteristics and commonalities of BSSs across various cases in urban China.

However, apart from the analysis by Munkácsy \& Monzón (2017) for a BSS in Madrid, Spain, there is still a research gap in discovering what is the impact of such new transportation systems on the everyday life of urban citizens.

The aim of this paper was to contribute to fill this gap by analysing the satisfaction among the 


\section{ACCEPTED MANUSCRIPT}

users of the bike-sharing service 'BikeMi' in Milan, Italy, using the results of a survey conducted in 2014 among service's subscribers.

According to a general question in the questionnaire there was a huge concordance about the positive rating of the service: $71 \%$ of the respondents gave a rating of 4 or 5 in a Likert scale ranging from 1 to 5. Satisfaction questions on specific parts of the service revealed high levels of satisfaction. Like in Munkácsy \& Monzón (2017) it can be hinted that users appreciate the implementation of a BSS, and survey respondents highly rated some of the characteristics of this service, such as the highly technological tools used for its functioning.

The use of general questions on satisfaction and simple/weighted averages of customer ratings has long been a mode of analysis in multiple disciplines (Clifton \& Díaz-Fuentes, 2010; Delgado et al., 1993). While this type of analysis gives some quick evidence on satisfaction, satisfaction is a more complex and hardly manageable concept, especially in the public sector.

According to the bottom-up spillover theory - a theory very well established in the wellbeing and quality-of-life literature - the overall satisfaction can be decomposed into a variety of latent traits, which not necessarily are congruent with the overall satisfaction (Andrew \& Withey, 1976; Campbell et al., 1976). Sirgy et al. (2000) argue that there exists even a more strong relationship between life satisfaction and satisfaction with a specific government service, especially when mediated by a community life domain, that is, the sense of belonging to a community. To develop a satisfaction analysis using techniques which take into due account the 'hidden world' of satisfaction is therefore important. NLPCA was chosen for the reason that it is a statistical method aiming at unveiling latent traits underlying a given concept (in our case the satisfaction for the BikeMi service) and, at the same time, producing a 'new map' of the 'real' 


\section{ACCEPTED MANUSCRIPT}

ratings the users intended to give with their responses.

Results of our analysis revealed the presence of grey areas or issues that could hinder satisfaction or go untraced or include bias even though, in general, the scheme's overall appeal to its users, despite these flaws, still seems to be high. These issues are mostly related to the mechanics of the bikes used for the service (even other aspects not directly regarding the bike, like the picking and dropping system and the apps used to organize the service) mostly affected the satisfaction. Less concern was unveiled for general aspects like the service as a valid alternative to the car in the city centre. A confirmatory textual analysis on an open question inserted in the questionnaire for comments and suggestions seemed to validate these results. Overall, the tripartite statistical analysis (simple average of the responses, NLPCA and text analysis) confirmed that subscribers told the truth about their opinions about the BikeMi service.

Future work will involve the development of two new surveys - an updated customer service survey among subscribers and a more general survey among the population of the city which will take in consideration concerns and questions raised by respondents in this survey (the use of e-bikes, the extension of the service, its integration with other forms of public transportation, etc.). A more thorough textual analysis will be performed using new big data techniques like sentiment analysis and opinion mining (Curini et al., 2015), also analysing new available social media sources of data like those from Twitter.

\section{Acknowledgements}

The authors would like to thank Sergio Verrecchia, Contracts, Development and Bike Sharing Director, Clear Channel Italia, for giving permission to use the survey data set, Fabio Cannetti, Bike Sharing Customer Care Manager, Clear Channel Italia, and Giuseppe Mistretta, Bike 


\section{ACCEPTED MANUSCRIPT}

Sharing Operations Manager, for their precious suggestions in developing and delivering the survey.

The authors also would like to thank the Editor and three anonymous referees for valuable suggestions and comments on earlier drafts of the paper. 


\section{ACCEPTED MANUSCRIPT}

\section{References}

American Community Survey (2014). Modes Less Traveled—Bicycling and Walking to Work in the United States: 2008-2012. ACS-25, 1-18. U.S. Census Bureau.

Andrew, F. M. \& Withey, S. B. (1976) Social Indicators of Well-Being: America's Perception of Life Quality. New York: Plenum Press.

Ansolabehere, S. \& Konisky, D. M. (2009). Public attitudes toward construction of new power plants. Public Opinion Quarterly, 73(3), 566-577, doi: 10.1093/poq/nfp041.

Bachand-Marleau, J., Lee, B. \& El-Geneidy, A. (2012). Better understanding of factors influencing likelihood of using shared bicycle systems and frequency of use. Transportation Research Record: Journal of the Transportation Research Board, 2314, 66-71. doi: 10.3141/2314-09.

Beroud, B. \& Anaya, E. (2012). Private interventions in a public service: An analysis of public bicycle schemes. In Parkin, J. (Ed.): Cycling and sustainability, London: Emerald: 269-301.

Bischoff, A. L. (2014). Cause-related Marketing. The Influence of the fit among partners, brands and cause. Hamburg, Germany: Anchor Academic Publishing.

Caggiani, L. \& Ottomanelli, M. (2013). A dynamic simulation based model for optimal fleet repositioning in bike-sharing systems. Procedia - Social and Behavioral Sciences, 87, 203-210. doi: $10.1016 /$ j.sbspro.2013.10.604.

Campbell, A., Converse, P. E. \& Rodgers, W. L. (1976). The Quality of American Life: Perspectives, Evaluations, and Satisfactions. New York: Russel Sage Foundation.

Cattell, R. B. (1966). The scree test for the number of factors. Multivariate Behavioral Research, 1(2), 245-276. doi: 10.1207/s15327906mbr0102_10. 


\section{ACCEPTED MANUSCRIPT}

Cheng. Y.-H. \& Liu, K.-C. (2012). Evaluating Bicycle-Transit Users? Perceptions of Intermodal Inconvenience. Transportation Research Part A, 46, 1690-1706. doi: 10.1016/j.tra.2012.10.013. Clifton, J. \& Díaz-Fuentes, D. D. (2010). Evaluating EU Policies on Public Services: A Citizens' Perspective. Annals of Public and Cooperative Economics, 81(2), 281-311. doi: 10.1111/j.14678292.2010.00412.x.

Chica-Olmo, J., Gachs-Sánchez, H. \& Lizarraga (2017). Route effect on the perception of public transport services quality. Transport Policy. doi: 10.1016/j.tranpol.2017.03.024.

Croci, E. \& Rossi, D. (2014). Optimizing the position of bike sharing stations. The Milan case. Bocconi Working Paper Series, WP no. 68, Bocconi University, Milan.

Curini, L., Iacus, S. \& Canova, L. (2015). Measuring Idiosyncratic Happiness Through the Analysis of Twitter: An Application to the Italian Case. Social Indicators Research, 121(2), 525542. doi: $10.1007 / \mathrm{s} 11205-014-0646-2$.

Delgado, A., Lopez-Fernandez, L. A. \& Luna, J. D. (1993). Influence of the Doctor's Gender in the Satisfaction of the Users. Medical Care, 31(9): 795- 800.

DeMaio, P. J. (2003). Smart Bikes: Public Transportation for the 21st Century. Transportation Quarterly, 57(1), 9-11.

DeMaio, P. J. (2009). Bike-sharing: History, Impacts, Models of Provision, and Future. Journal of Public Transportation, 12(4): 41-56. doi: 10.5038/2375-0901.12.4.3.

Efthymiou, D., Antoniou, C., \& Waddell, P. (2013). Factors affecting the adoption of vehicle sharing systems by young drivers. Transport Policy, 29, 64-73. doi: 10.1016/j.tranpol.2013.04.009.

El-Assi W., Mahmoud, M.S. \& Habib, K.N. (2015). Effects of Built Environment and Weather 


\section{ACCEPTED MANUSCRIPT}

on Bike Sharing Demand: Station Level Analysis of Commercial Bike Sharing in Toronto. Transportation Research Board 94th Annual Meeting Compendium of Papers. doi: 10.1007/s11116- 015-9669-z.

Ferrari, P. A. \& Manzi, G. (2014). Citizens Evaluate Public Services: A Critical Overview of Statistical Methods for Analysing User Satisfaction. Journal of Economic Policy Reform, 17(3), 236-252, doi: 10.1080/17487870.2014.909313.

Ferrari, P. A., Annoni, P. \& Manzi, G. (2010). Evaluation and Comparison of European Countries: Public Opinion on Services. Quality \& Quantity, 44, 1191-1205. doi: 10.1007/s11135-009-9278-z.

Fishman, E., Washington S. \& Narelle, H. (2014). Bike share's impact on car use: evidence from the United States, Great Britain, and Australia. Transportation Research - Part D, 31: 13-20, doi: 10.1016/j.trd.2014.05.013.

García-Palomares, J. C., Gutiérrez, J. \& Latorre, M. (2012). Optimizing the location of stations in bike-sharing programs: A GIS approach. Applied Geography, 35, 235-246. doi: 10.1016/j.apgeog.2012.07.002.

Goldsmith, E. B. (2015). Social Influence and Sustainable Consumption. Cham, Switzerland: Springer.

Grigoroudis, E. \& Siskos, Y. (2004). A Survey of Customer Satisfaction Barometers: Some Results from the Transportation-Communications Sector. European Journal of Operational Research, 152(2), 334-353. doi: 10.1016/S0377-2217(03)00028-6.

Harwell, M. R. \& Gatti, G. G. (2001). Rescaling Ordinal Data to Interval Data in Educational Research. Review of Educational Research, 71(1), 105- 13. doi: 10.3102/00346543071001105. 


\section{ACCEPTED MANUSCRIPT}

Heiser, W. J., \& Meulman, J. J. (1994). Homogeneity analysis: Exploring the distribution of variables and their nonlinear relationships. In M. Greenacre \& J. Blasius (Eds.), Correspondence analysis in the social sciences: Recent developments and applications, New York: Academic Press.

Ho, S. S., Chen, V. H.-H. \& Sim, C. C. (2013). The Spiral of Silence: Examining How Cultural Predispositions, News Attention, and Opinion Congruency Relate to Opinion Expression. Asian Journal of Communication, 23(2), 113-134. doi: 10.1080/01292986.2012.725178.

ITDP (2014). The Bike-Share Planning Guide. Institute for Transportation and Development Policy.

Jamerson, F. E., \& Benjamin, E. (2015). Electric bikes worldwide reports. Retrieved from http://www.ebwr.com/.

Ji, S., Cherry, R. C., Han L. D. \& Jordan, D. A. (2014). Electric bike sharing: simulation of user demand and system availability. Journal of Cleaner Production, 85, 250-257. doi: 10.1016/j.jclepro.2013.09.024

Jolliffe, I. T. (2002). Principal Component Analisys - Second Edition. New York: Springer.

Kaiser, H.F. (1960). The application of electronic computers to factor analysis. Educational and Psychological Measurement, 20(1), 141-151. doi:10.1177/001316446002000116.

Kaiser, H.F. (1958). The varimax criterion for analytic rotation in factor analysis. Psychometrika, 23(3), 187-200. doi:10.1007/BF02289233.

Kim, D., Ko, J. \& Park, Y. (2015). Factors affecting electric vehicle sharing program participants' attitudes about car ownership and program participation. Transportation Research Part D, 36, 96-106. doi: 10.1016/j.trd.2015.02.009. 


\section{ACCEPTED MANUSCRIPT}

Kim, S. H., Chung, J.-H., Park, S. \& Choi, K. (2017a). Analysis of User Satisfaction to Promote Public Transportation: A Pattern-Recognition Approach Focusing on Out-of-Vehicle Time. International Journal of Sustainable Transportation. Accepted Manuscript.

Kim, J., Choi, K., Kim, S. \& Fujii, S. (2017b). How to promote sustainable public bike system from a psychological perspective? International Journal of Sustainable Transportation, 11(4), 272-281. doi: 10.1080/15568318.2016.1252450.

Kingham, S., Dickinson J. \& Copsey, S. (2001). Travelling to work: will people move out of their cars. Transport Policy, 8(2), 151-160. doi: 10.1016/S0967-070X(01)00005-1.

Krizek, K. \& Stonebraker, E. (2011). Assessing Options to Enhance Bicycle and Transit Integration. Transportation Research Record: Journal of the Transportation Research Board, 2217, 162-167. doi: 10.3141/2217-20.

Lathia, N., Ahmed, S. \& Capra, L. (2012). Measuring the Impact of Opening the London Shared Bicycle Scheme to Casual Users. Transportation Research - Part C, 22, 88-102. doi: 10.1016/j.trc.2011.12.004.

League of American Bicyclists (2014). Where we ride. Analysis of bicycle commuting in American cities. 1-41. Retrieved from

http://bikeleague.org/sites/default/files/Where_We_Ride_2014_data_web.pdf\#12. Accessed on April $24^{\text {th }}, 2017$.

Likert, R. (1932). A Technique for the Measurement of Attitudes. Archives of Psychology, 140, 595-639.

Locke, E. A. (1967). Relationship of Success and Expectation to Affect on Goal Seeking Tasks. Journal of Personality and Social Psychology, 7(2), 125-134. 


\section{ACCEPTED MANUSCRIPT}

Manisera, M., Van Der Kooij, A. J. \& Dusseldorp, E. (2010). Identifying the Component

Structure of Satisfaction Scales by Nonlinear Principal Components Analysis. Quality Technology \& Quantitative Management, 7(2), 97-115. doi: 10.1080/16843703.2010.11673222.

Metrobike (2017). Public Use Bicycles 2016. Retrieved from http://bike-sharing.blogspot.it. Accessed on April 25 $5^{\text {th }}, 2017$.

Michailidis, G. \& De Leeuw, J. (1998). The Gifi system of descriptive multivariate analysis. Statistical Science, 13, 307-336.

Midgley, P. (2011). Bicycle-Sharing Schemes: Enhancing Sustainable Mobility in Urban Areas. United Nations, Commission on Sustainable Development, Background paper n. 8.

Munkácsy, A. \& Monzón, A. (2017). Potential User Profiles of Innovative Bike-Sharing Systems: The Case of BICIMAD (Madrid, Spain). Asian Transport Studies, 4(3): 621-638. doi: 10.11175/eastsats.4.621.

Murphy, E. \& Usher, J. (2015). The Role of Bicycle-sharing in the City: Analysis of the Irish Experience. International Journal of Sustainable Transportation, 9, 116-125, doi: 10.1080/15568318.2012.748855.

Nakamura, H., \& Abe, N. (2014). The role of a non-profit organisation-run public bicyclesharing programme: the case of Kitakyushu City, Japan. Journal of Transport Geography, 41, 338-345. doi: 10.1016/j.jtrangeo.2013.11.009.

Navigant Research (2013). Electric Bicycles: Global Market Opportunities, Barriers, Technology Issues, and Demand Forecasts for E-Bicycles, Pedal-Assist Bicycles and E-Bicycle Batteries and Motors. Retrieved from http://www.navigantresearch.com/research/electric-bicycles.

Nikitas A., Wallgren P. \& Rexfelt O. (2016). The paradox of public acceptance of bike-sharing 


\section{ACCEPTED MANUSCRIPT}

in Gothenburg. Proceedings of the Institution of Civil Engineers - Engineering Sustainability, 169(3), 101-113. Doi: 10.1680/jensu.14.00070.

Noelle-Neumann, E. (1974). The Spiral of Silence: A Theory of Public Opinion. Journal of Communication, 24(2), 43-51. doi: 10.1111/j.1460-2466.1974.tb00367.x.

Pucher, J., Buehler, R., Merom, D. \& Bauman, A. (2011). Walking and Cycling in the United States, 2001-2009: Evidence From the National Household Travel Surveys. American Journal of Public Health, 101(1), 310-317.

Pulina, M (2011). Consumer behaviour in the credit card market: a banking case study. International Journal of Consumer Studies, 35: 86-94. doi: 10.1111/j.1470-6431.2010.00939.x. Rao, A. \& Bergen, M. (1992). Price premium variations as a consequence of buyers' lack of information. Journal of Consumer Research, 18: 412-423. Doi: 0093-5301/93/1903.

Ricci, M. (2015). Bike sharing: a review of evidence on impacts and processes of implementation and operation. Research in Transportation Business \& Management, 15, 28-38. doi: 10.1016/j.rtbm.2015.03.003.

Richardson, A.J., Ampt, E.S. \& Meyburg, A.H. (1995). Survey methods for transport planning. Melbourne: Eucalyptus Press, 1995.

Saibene, G. \& Manzi, G. (2014). Il bike sharing di Milano: rapporto sullo sviluppo di un nuovo sistema di trasporto pubblico di successo [The Milan Bike-Sharing: Report on the Development of a New Successful Public Transport System]. Rivista di Economia e Politica dei Trasporti, 3(8): 1-24 (In Italian).

Saibene, G. \& Manzi, G. (2015). Bike Usage in Public Bike-Sharing: An Analysis of the “BikeMi” System in Milan. DEMM Working Paper Series, University of Milan, WP no. 2015- 


\section{ACCEPTED MANUSCRIPT}

01.

Sale, P.F. (2011). Our Dying Planet. An Ecologist's View of the Crisis We Face. Berkeley, CA: University of California Press.

Shaheen, S. A. \& Guzman, S. (2011). Worldwide bikesharing. Access Magazine, 1(39): 22-27.

Shaheen, S. A., Zhang, H., Martin, E. \& Guzman, S. (2011). Hangzhou Public Bicycle: Understanding Early Adoption and Behavioral Response to Bikesharing in Hangzhou, China. Transportation Research Record: Journal of the Transportation Research Board, No. 2247: 33 41. doi: $10.3141 / 2247-05$.

Shaheen, S. A., Guzman, S. \& Zhang, H. (2010). Bikesharing in Europe, the Americas, and Asia: Past, Present, and Future. Transportation Research Record: Journal of the Transportation Research Board, 2143, 159-167. doi: 10.3141/2143-20

Sirgy, M. J., Rahtz, D. R., Cicic, M. \& Underwood, R. (2000). A method for assessing residents' satisfaction with community-based services: a quality-of- life perspective. Social Indicators Research, 49(3), 279-316. doi: 10.1023/A:1006990718673.

Smith, M.S. \& Kauermann, G. (2011). Bicycle Commuting in Melbourne During the 2000s Energy Crisis: A Semiparametric Analysis of Intraday Volumes. Journal of Transportation Research - Part B, 45(10): 1846-1862. doi: 10.1016/j.trb.2011.07.003.

Stevens, J. (1992). Applied Multivariate Statistics for the Social Sciences - Second edition. Hillsdale, NJ: Lawrence Erlbaum Associates, Inc.

Tironi, M. (2015). (De)politicising and Ecologising Bicycles. Journal of Cultural Economy, 8(2): 166-183. doi: 10.1080/17530350.2013.838600.

Van de Walle, S. \& Van Ryzin, G. G. (2011). The Order of Questions in a Survey on Citizen 


\section{ACCEPTED MANUSCRIPT}

Satisfaction with Public Services: Lessons from a Split- Ballot Experiment. Public Administration, 89(4) 1436-1450. doi: 10.1111/j.1467-9299.2011.01922.x.

Van Ryzin, G. G. \& Charbonneau, É. (2010). Public service use and perceived performance: An empirical note on the nature of the relationship. Public Administration, 88(2), 551-563. doi: 10.1111/j.1467-9299.2010.01820.x.

Vlosky, R., Ozanne, L. \& Fontenot, R. (1999). A conceptual model of US consumer willingnessto-pay for environmentally certified wood products. Journal of Consumer Marketing, 16(2): 122-136. doi: 10.1108/07363769910260498.

Yang, R., \& Long, R. (2016). Analysis of the Influencing Factors of the Public Willingness to Participate in Public Bicycle Projects and Intervention Strategies-A Case Study of Jiangsu Province, China. Sustainability, 8(4), 349-364. doi: 10.3390/su8040349.

Wardman, M. (1988), A Comparison of Revealed and Stated Preference Models of Travel Behaviour. Journal of Transport Economics and Policy, 22, 71-91.

Zhang, D., Xu, X., \& Yang, X. (2015a). User satisfaction and its impacts on the use of a public bicycle system: empirical studies from Hangzhou, China. Transportation Research Record: Journal of the Transportation Research Board, (2512), 56-65. doi: 10.3141/2512-07.

Zhang, H., Shaheen, S. A. \& Chen, X. (2014). Bicycle Evolution in China: From the 1900s to the Present, International Journal of Sustainable Transportation, 8, 317-335. doi: 10.1080/15568318.2012.699999.

Zhang, L., Zhang, J., Duan, Z. Y., \& Bryde, D. (2015b). Sustainable bike-sharing systems: characteristics and commonalities across cases in urban China. Journal of Cleaner Production, 97, 124-133. doi: 10.1016/j.jclepro.2014.04.006. 


\section{ACCEPTED MANUSCRIPT}

Appendix: Survey questionnaire

See Tables 10, 11 and 12. 


\section{ACCEPTED MANUSCRIPT}

Table 1. The four BSS generations. Source: adapted from Beroud \& Anaya (2012), Midgley

(2011), Shaheen et al. (2010) and Zhang et al. (2013)

\begin{tabular}{|c|c|c|c|c|}
\hline BSS generation & Period & Technology & $\begin{array}{c}\text { Payment system and other } \\
\text { characteristics }\end{array}$ & Most notorious examples \\
\hline 'White bikes' & $1964-91$ & $\begin{array}{ll} & \text { Simple bikes } \\
\text { - } & \text { No docking stations } \\
\text { - } & \text { No locks } \\
\end{array}$ & Free of charge & $\begin{array}{ll} & \text { Amsterdam (NL) } \\
\text { - } & \text { La Rochelle (FR) } \\
\text { - } & \text { Cambridge (UK) }\end{array}$ \\
\hline 'Coin deposit' & $1991-96$ & $\begin{array}{ll} & \text { Ad hoc bike components to } \\
\text { - } & \text { reduce thefts } \\
\text { - } & \text { Docking stations } \\
\end{array}$ & 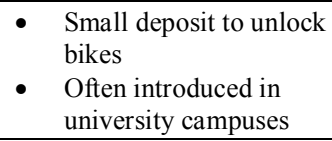 & $\begin{array}{ll} & \text { Farsø (DK) } \\
- & \text { Grenå (DK) } \\
\text { - } & \text { Nakskov (DK) } \\
\text { - } & \text { Copenhagen (DK) } \\
\end{array}$ \\
\hline 'IT-based' & $1996-2007$ & $\begin{array}{ll} & \text { User interface technology } \\
\text { - Smart tech: mobile phones, } \\
\text { stripe cards, smart cards, etc. }\end{array}$ & $\begin{array}{l}\text { Membership service or } \\
\text { annual fee with costs } \\
\text { increasing with use }\end{array}$ & $\begin{array}{ll} & \text { Rennes (FR) } \\
\text { - } & \text { Lyon (FR) } \\
\end{array}$ \\
\hline 'Multi-modal system' & $2007-16$ & $\begin{array}{l}\text { - Automated bike distribution } \\
\text { - Electric bikes } \\
\text { - User interface technology } \\
\text { - Smart tech: smart phones, } \\
\text { stripe cards, smart cards, etc. } \\
\text { - Interaction with other } \\
\text { transport systems } \\
\text { - } \text { GPS technology }\end{array}$ & $\begin{array}{l}\text { Membership service with } \\
\text { more varying offer }\end{array}$ & $\begin{array}{ll}\text { - } & \text { Paris (FR) } \\
\text { - } & \text { Barcelona (SP) } \\
\text { - } & \text { Washington (USA) }\end{array}$ \\
\hline
\end{tabular}




\section{ACCEPTED MANUSCRIPT}

Table 2. Descriptive statistics on Likert scale responses to satisfaction questions on a range from

1 ("Not at all satisfied") to 5 (Very satisfied).

\begin{tabular}{|c|c|c|c|c|c|c|}
\hline \multirow{2}{*}{ Question } & \multirow{2}{*}{$\begin{array}{l}\text { Aspect of the } \\
\text { service }\end{array}$} & \multirow{2}{*}{ Mode } & \multicolumn{3}{|c|}{ Percentiles } & \multirow{2}{*}{ Skewness } \\
\hline & & & 25th & 50th & 75th & \\
\hline Q8 & $\begin{array}{c}\text { Subscription fee } \\
\text { reasonability }\end{array}$ & 5 & 4 & 5 & 5 & -1.392 \\
\hline Q9 & $\begin{array}{l}\text { Bike comfort and } \\
\text { handling }\end{array}$ & 3 & 2 & 3 & 4 & -0.169 \\
\hline Q10 & $\begin{array}{c}\text { Customer care } \\
\text { service }\end{array}$ & 4 & 3 & 4 & 4 & -0.510 \\
\hline Q11 & $\begin{array}{l}\text { Station location and } \\
\text { accessibility }\end{array}$ & 4 & 3 & 4 & 4 & -0.518 \\
\hline Q12 & $\begin{array}{l}\text { Renting system } \\
\text { efficiency }\end{array}$ & 4 & 3 & 4 & 5 & -0.884 \\
\hline Q13 & $\begin{array}{l}\text { Bike quality and } \\
\text { functioning }\end{array}$ & 3 & 2 & 3 & 3 & 0.037 \\
\hline Q14 & $\begin{array}{l}\text { BikeMi as a valid } \\
\text { alternative to } \\
\text { private car }\end{array}$ & 5 & 4 & 5 & 5 & -1.344 \\
\hline Q15 & Overall satisfaction & 4 & 3 & 4 & 4 & -0.663 \\
\hline
\end{tabular}




\section{ACCEPTED MANUSCRIPT}

Table 3. Correlation matrix between responses to satisfaction questions

\begin{tabular}{|c|c|c|c|c|c|c|c|c|c|}
\hline & & Q8 & Q9 & Q10 & Q11 & Q12 & Q13 & Q14 & Q15 \\
\hline Q8 & $\rho$ & 1 & & & & & & & \\
\hline & $N$ & 9947 & & & & & & & \\
\hline Q9 & $\rho$ & 0.307 & 1 & & & & & & \\
\hline & $N$ & 9909 & 9941 & & & & & & \\
\hline Q10 & $\rho$ & 0.320 & 0.378 & 1 & & & & & \\
\hline & $N$ & 9722 & 9717 & 9753 & & & & & \\
\hline Q11 & $\rho$ & 0.282 & 0.235 & 0.312 & 1 & & & & \\
\hline & $N$ & 9887 & 9887 & 9699 & 9921 & & & & \\
\hline Q12 & $\rho$ & 0.279 & 0.322 & 0.329 & 0.341 & 1 & & & \\
\hline & $N$ & 9890 & 9888 & 9701 & 9869 & 9924 & & & \\
\hline Q13 & $\rho$ & 0.150 & 0.521 & 0.317 & 0.217 & 0.316 & 1 & & \\
\hline & $N$ & 9903 & 9904 & 9715 & 9883 & 9887 & 9938 & & \\
\hline Q14 & $\rho$ & 0.298 & 0.220 & 0.261 & 0.272 & 0.233 & 0.132 & 1 & \\
\hline & $N$ & 9907 & 9907 & 9714 & 9886 & 9889 & 9901 & 9941 & \\
\hline Q15 & $\rho$ & 0.382 & 0.503 & 0.491 & 0.424 & 0.459 & 0.472 & 0.456 & 1 \\
\hline & $N$ & 9916 & 9910 & 9726 & 9893 & 9895 & 9909 & 9912 & 9951 \\
\hline
\end{tabular}

Note: all coefficients are significant at $p<0.001$. 


\section{ACCEPTED MANUSCRIPT}

Table 4. Cronbach's alpha and eigenvalues for a NLPCA performed on the satisfaction variables

\begin{tabular}{|c|c|c|}
\hline Component & Cronbach's alpha & Eigenvalue \\
\hline 1 & 0.688 & 2.436 \\
2 & 0.122 & 1.118 \\
3 & -0.109 & 0.916 \\
4 & -0.310 & 0.790 \\
5 & -0.472 & 0.713 \\
6 & -0.601 & 0.660 \\
7 & -1.323 & 0.469 \\
\hline Total & 1.002 & 7.100 \\
\hline
\end{tabular}




\section{ACCEPTED MANUSCRIPT}

Table 5. Rotated component loadings for the two-component solution

\begin{tabular}{|c|c|c|}
\hline \multirow{2}{*}{ Variable } & \multicolumn{2}{|c|}{ Component } \\
\cline { 2 - 3 } & $\mathbf{1}$ & $\mathbf{2}$ \\
\hline Q8 & 0.129 & $\mathbf{0 . 7 2 3}$ \\
Q9 & $\mathbf{0 . 7 9 5}$ & 0.172 \\
Q10 & $\mathbf{0 . 5 1 3}$ & 0.447 \\
Q11 & 0.242 & $\mathbf{0 . 6 0 8}$ \\
Q13 & $\mathbf{0 . 4 9 4}$ & 0.433 \\
Q14 & $\mathbf{0 . 8 6 2}$ & -0.024 \\
\hline
\end{tabular}




\section{ACCEPTED MANUSCRIPT}

Table 6. Conditional averages of scores - Demographic conditioning variables

\begin{tabular}{|c|c|c|c|}
\hline \multirow{2}{*}{$\begin{array}{c}\text { Conditioning } \\
\text { variable }\end{array}$} & \multirow{2}{*}{ Category } & \multicolumn{2}{|c|}{ Average object score } \\
\hline & & Everyday & General \\
\hline \multirow{2}{*}{ Q1 - Gender } & Female & -0.0542 & -0.0104 \\
\hline & Male & 0.3080 & 0.0046 \\
\hline \multirow{3}{*}{ Q2 - Age } & Less than 30 yrs. & -0.118 & 0.0312 \\
\hline & 30-49 yrs. & 0.0086 & -0.016 \\
\hline & More than 49 yrs. & -0.0193 & 0.0112 \\
\hline \multirow{3}{*}{ Q3 - Education } & Primary/Lower secondary & -0.1897 & -0.0951 \\
\hline & Upper secondary & -0.0287 & -0.0134 \\
\hline & Tertiary & 0.0105 & 0.0048 \\
\hline \multirow{8}{*}{ Q4 - Job status } & Manager & 0.0576 & 0.0365 \\
\hline & Self-employed & -0.0395 & 0.0369 \\
\hline & Employee & -0.0134 & -0.0340 \\
\hline & Civil servant & -0.0202 & -0.1180 \\
\hline & Student & 0.0027 & 0.0606 \\
\hline & Retired & -0.0057 & -0.1865 \\
\hline & Unemployed & 0.0206 & -0.2102 \\
\hline & Other & -0.0077 & -0.0094 \\
\hline \multirow{3}{*}{ Q5 - Marital status } & Married & 0.0419 & 0.0196 \\
\hline & Unmarried or widowed & -0.0397 & -0.0186 \\
\hline & Other & -0.0322 & -0.0183 \\
\hline
\end{tabular}




\section{ACCEPTED MANUSCRIPT}

Table 7. Conditional average of object scores - Usage conditioning variables

\begin{tabular}{|c|c|c|c|}
\hline \multirow{2}{*}{ Conditioning variable } & \multirow{2}{*}{ Category } & \multicolumn{2}{|c|}{ Average object score } \\
\hline & & Everyday & General \\
\hline \multirow{5}{*}{ Q16 - Reasons for using BikeMi } & To go to workplace & 0.0011 & 0.1149 \\
\hline & $\begin{array}{l}\text { To go to } \\
\text { school/university }\end{array}$ & 0.0265 & 0.1114 \\
\hline & To go shopping & 0.0027 & -0.0990 \\
\hline & $\begin{array}{c}\text { To have a nice } \\
\text { iourney }\end{array}$ & -0.0197 & -0.2883 \\
\hline & Other reason & 0.0149 & -0.0760 \\
\hline \multirow{5}{*}{ Q17 - Average distance } & $<1 \mathrm{~km}$ & -0.0796 & -0.1743 \\
\hline & $1-2 \mathrm{kms}$ & 0.0218 & -0.0152 \\
\hline & $2-4 \mathrm{kms}$ & 0.0088 & 0.0415 \\
\hline & $>4 \mathrm{~km}$ & -0.0274 & 0.0044 \\
\hline & Other distance & -0.1468 & -0.0510 \\
\hline \multirow{5}{*}{ Q18 - Average time } & $<5$ mins & -0.0529 & -0.1053 \\
\hline & 5-10 mins & 0.0331 & 0.0172 \\
\hline & $10-30 \mathrm{mins}$ & 0.0004 & 0.0126 \\
\hline & $>30 \mathrm{mins}$ & -0.2711 & -0.2742 \\
\hline & Other time & -0.1971 & -0.1701 \\
\hline \multirow{2}{*}{ Q19 - Breaks or diversions? } & Yes & 0.0151 & -0.1238 \\
\hline & No & -0.0004 & 0.0424 \\
\hline \multirow{6}{*}{ Q20 - Frequency } & Almost everyday & 0.0760 & 0.1743 \\
\hline & Working days & 0.0278 & 0.1039 \\
\hline & Weekends & 0.0388 & -0.0927 \\
\hline & Every now and then & -0.0284 & -0.1106 \\
\hline & Almost never & -0.7212 & -0.7995 \\
\hline & Other frequency & -0.0142 & -0.0102 \\
\hline \multirow{2}{*}{ Q21 - Other transport used? } & Yes & -0.0046 & -0.0144 \\
\hline & No & 0.0137 & 0.0816 \\
\hline \multirow{6}{*}{ Q22 - Reasons for subscription } & Bike enthusiastic & 0.0602 & -0.0194 \\
\hline & $\begin{array}{c}\text { Faster transport } \\
\text { mode }\end{array}$ & 0.0033 & 0.0880 \\
\hline & Ecological choice & 0.0436 & -0.0247 \\
\hline & $\begin{array}{l}\text { Good with other } \\
\text { transport }\end{array}$ & 0.0233 & -0.0522 \\
\hline & Good for health & -0.0582 & -0.0473 \\
\hline & Other reasons & -0.1658 & -0.1009 \\
\hline \multirow{3}{*}{ Q23 - Downsides of BikeMi } & Dangerous transport & -0.0812 & 0.0361 \\
\hline & Lack of cycle lanes & 0.0197 & 0.0163 \\
\hline & Bad for your health & 0.0190 & -0.0501 \\
\hline
\end{tabular}




\section{ACCEPTED MANUSCRIPT}

\begin{tabular}{|c|c|c|c|}
\hline & Too slow & -0.1106 & -0.1644 \\
& Other downsides & 0.0080 & -0.1200 \\
\hline \multirow{2}{*}{ Q24 - Would you use e-bikes? } & Yes & -0.0394 & -0.0142 \\
& No & 0.0717 & 0.0343 \\
\hline Q25 - Would you pay more for & Yes & 0.0747 & 0.0162 \\
e-bikes? & No & -0.0389 & -0.0045 \\
\hline
\end{tabular}




\section{ACCEPTED MANUSCRIPT}

Table 8. Average quantifications: simple average and NLPCA

\begin{tabular}{|c|c|c|}
\hline Question & Simple average & NLPCA \\
\hline Q8 & 0.832 & 0.898 \\
Q9 & 0.530 & 0.501 \\
Q10 & 0.676 & 0.693 \\
Q11 & 0.636 & 0.699 \\
Q12 & 0.726 & 0.728 \\
Q13 & 0.443 & 0.441 \\
Q14 & 0.814 & 0.899 \\
\hline Total average & 0.665 & 0.694 \\
Average of everyday aspects & 0.594 & 0.590 \\
Average of general aspects & 0.761 & 0.832 \\
\hline
\end{tabular}




\section{ACCEPTED MANUSCRIPT}

Table 9. Textual analysis on the open question (Q26) for comments: distribution of concerns and opinion about the service $(6,364$ respondents $-63.6 \%$ - out of 10,055 participants answering question Q26)

\begin{tabular}{|c|c|c|c|}
\hline $\begin{array}{c}\text { Concern/Improvement } \\
\text { needed }\end{array}$ & Percentage & Opinion & Percentage \\
\hline Bike comfort and & 32.4 & Good & 88.5 \\
functioning & 0.8 & Bad & 11.5 \\
Cost of subscription & 1.9 & & \\
Customer care and call & 5.1 & & \\
center & 0.6 & & \\
Lack of cycling lanes & 7.4 & \\
Cycling is dangerous & 20.1 & \\
Opening hours & 13.9 & & \\
More docking station & 1.8 & & \\
Picking/dropping & 11.7 & & \\
system and apps & & \\
State of the roads & & \\
Station maintenance & & \\
and bike distribution & Forms of subscription & & \\
\hline
\end{tabular}




\section{ACCEPTED MANUSCRIPT}

Table 10. Sections A and B of the questionnaire

\begin{tabular}{|c|}
\hline SECTION A - PERSONAL INFORMATION \\
\hline 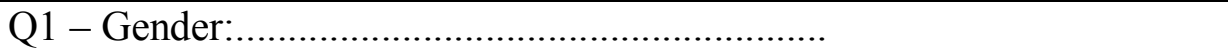 \\
\hline Q2 - Age: \\
\hline Q3 - Education: \\
\hline Q4 - Job status: \\
\hline Q5 - Marital status: \\
\hline 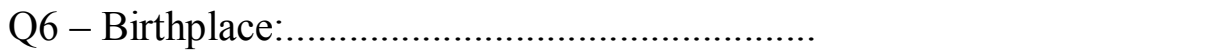 \\
\hline 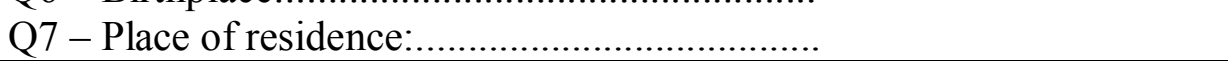 \\
\hline SECTION B - SATISFACTION WITH THE SERVICE \\
\hline Q8 - Subscription fee is reasonable \\
\hline [1] [2] [3] [4] [5] \\
\hline Q9 - Bicycles are handy and comfortable \\
\hline [1] [2] [3] [4] [5] \\
\hline Q10 - How do you rate the customer care service? \\
\hline [1] [2] [3] [4] [5] \\
\hline Q11 - Bike stations are well located in the city \\
\hline [1] [2] [3] [4] [5] \\
\hline Q12 - Renting, picking and leaving a bike is easy, fast and efficient \\
\hline [1] [2] [3] [4] [5] \\
\hline Q13 - Bicycles operate well (brakes, lights, pedals, etc.) \\
\hline [1] [2] [3] [4] [5] \\
\hline Q14 - The BikeMi service is a valid alternative to private car \\
\hline [1] [2] [3] [4] [5] \\
\hline Q15 - Generally speaking, how much are you satisfied with the service? \\
\hline
\end{tabular}




\section{ACCEPTED MANUSCRIPT}

Table 11. Section C of the questionnaire (part I)

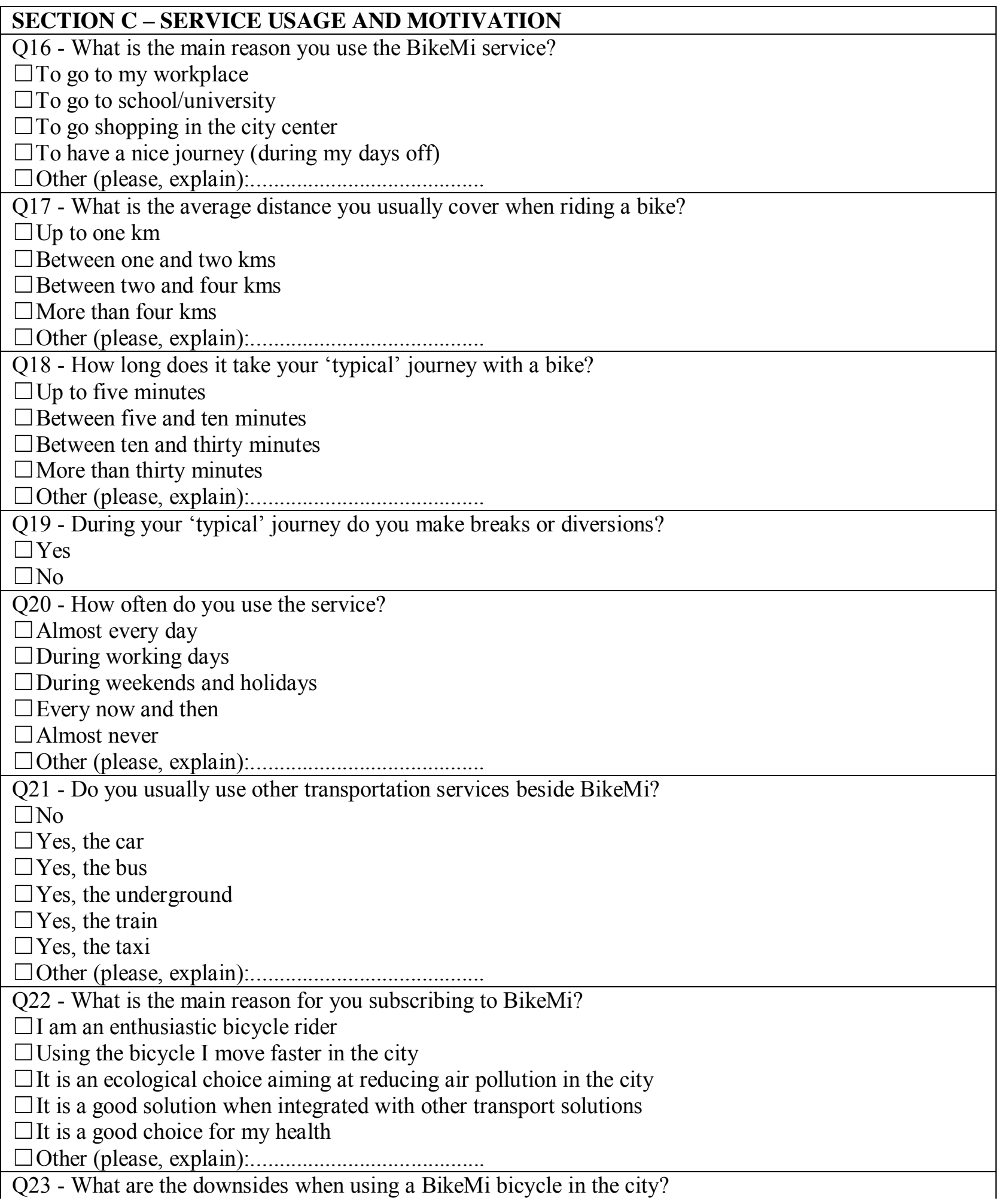




\section{ACCEPTED MANUSCRIPT}

$\square$ It is a dangerous means of transport

$\square$ The lack of dedicated and safe bicycle paths

$\square$ It is bad for your health due to the city air pollution

$\square$ It is too slow

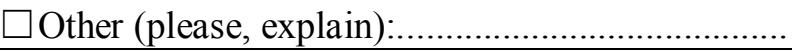




\section{ACCEPTED MANUSCRIPT}

Table 12. Section $\mathrm{C}$ of the questionnaire (part II)

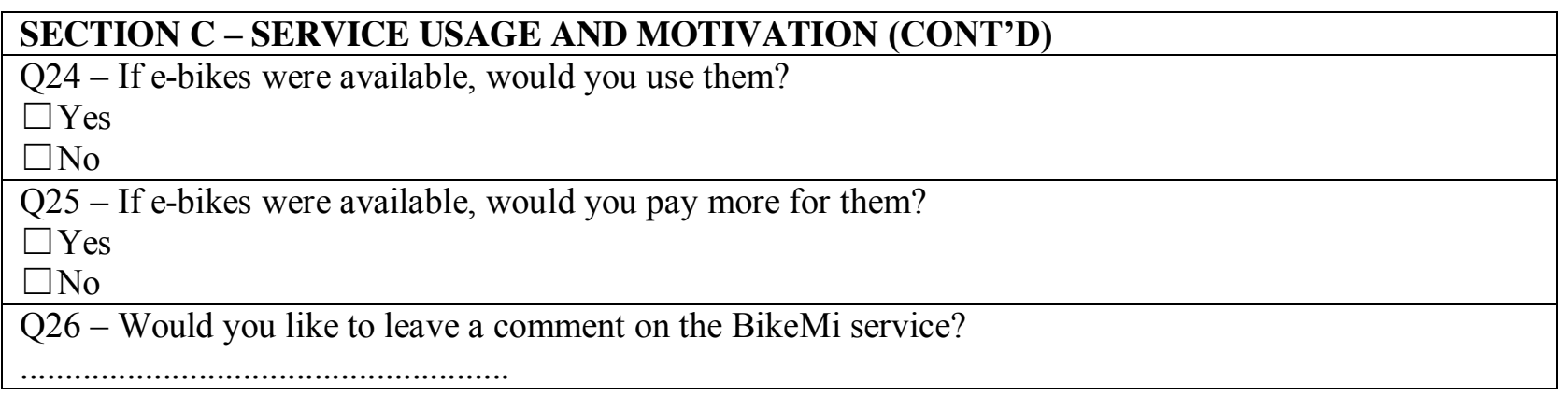




\section{ACCEPTED MANUSCRIPT}

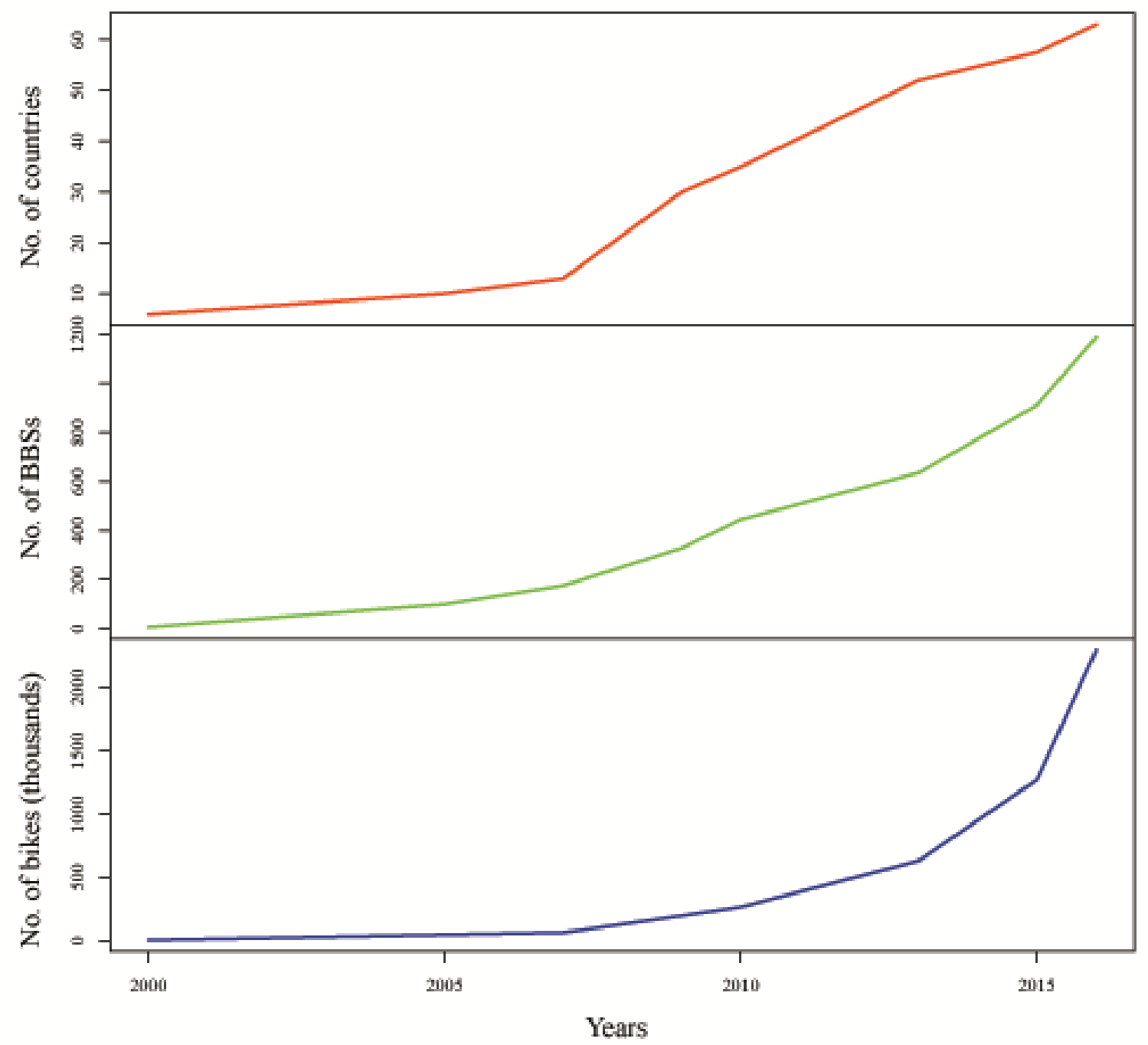

Figure 1: Evolution of the number of countries adopting BSSs, the total number of BSSs and the number of circulating BSS bikes between 2000 and 2016 - World. Sources: http://bikesharing.blogspot.it; https://www.google.com/maps/d/viewer?hl=en\&mid=1UxYw9YrwT_R3SGsktJU3D2GpMU\&11 $=18.794638322687764 \% 2 \mathrm{C} 83.67191386171862 \& \mathrm{z}=9$ 


\section{ACCEPTED MANUSCRIPT}

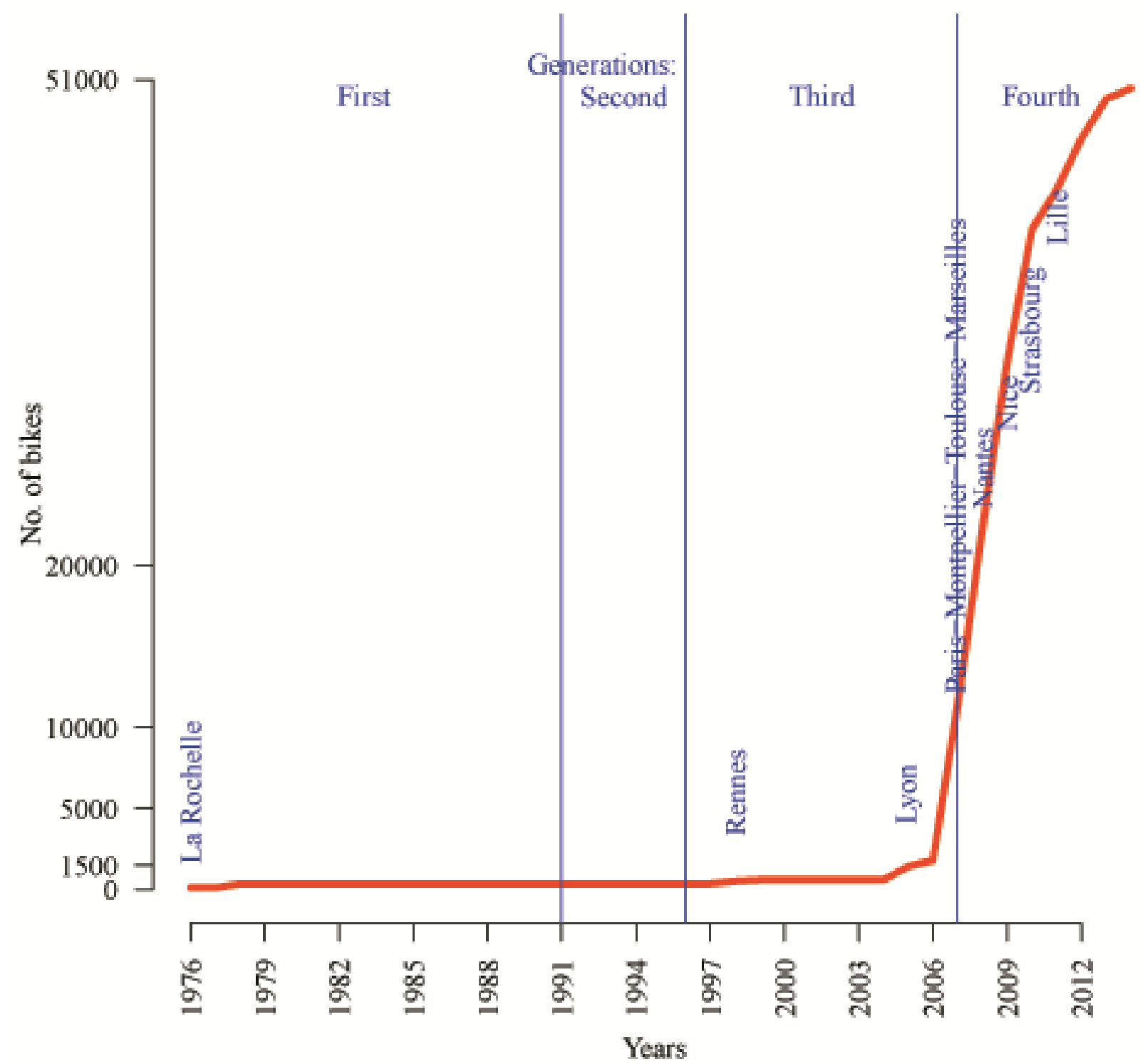

Figure 2: Evolution of the number of circulating BSS bikes in French cities between 1976 and 2014. Source: Computed by authors based on various BSS French municipality websites 


\section{ACCEPTED MANUSCRIPT}

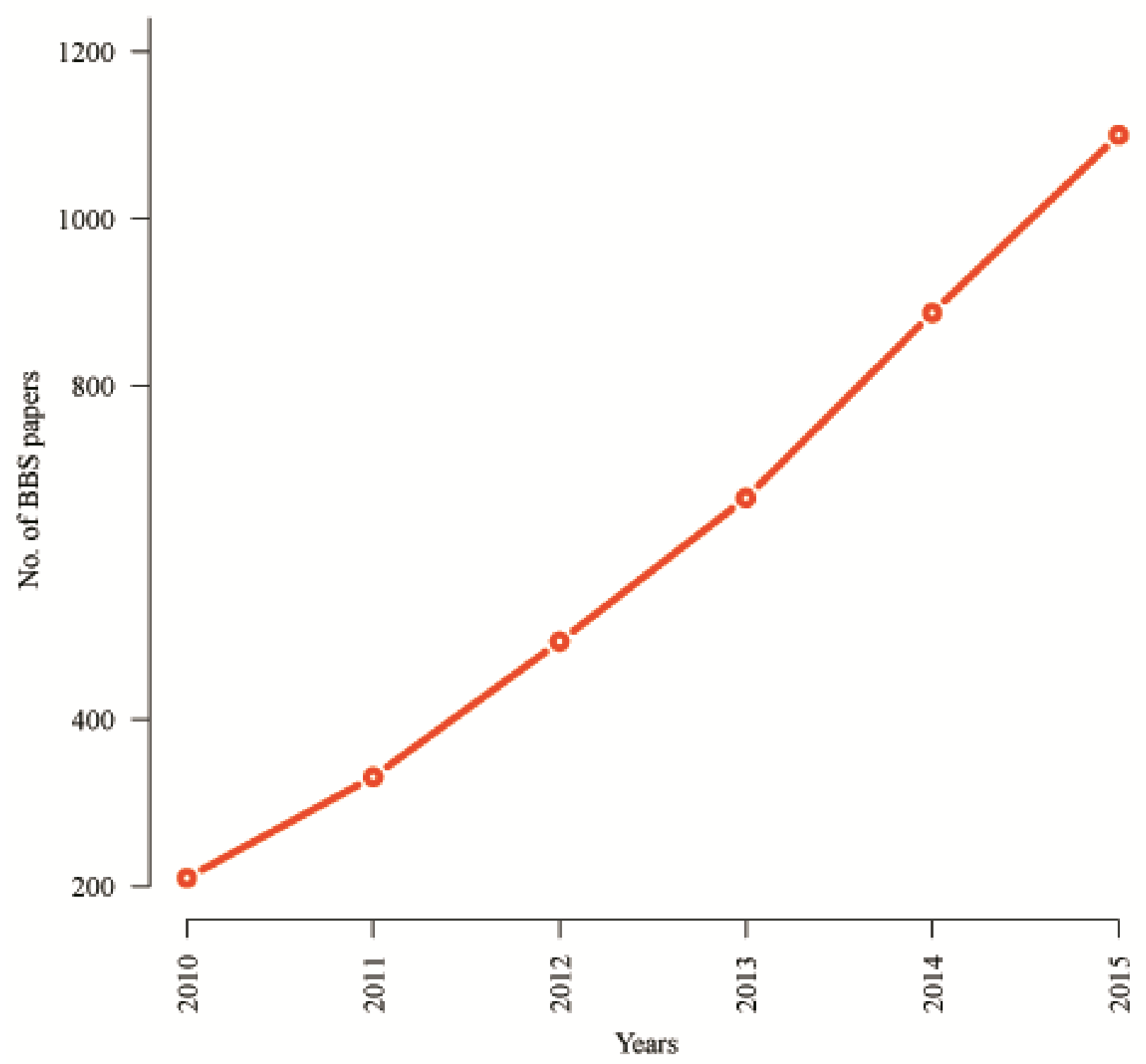

Figure 3: Published papers on BSSs, according to a yearly-based query on Google Scholar using the search term "bike sharing" - Years 2010-2015. Source: Google Scholar 


\section{ACCEPTED MANUSCRIPT}

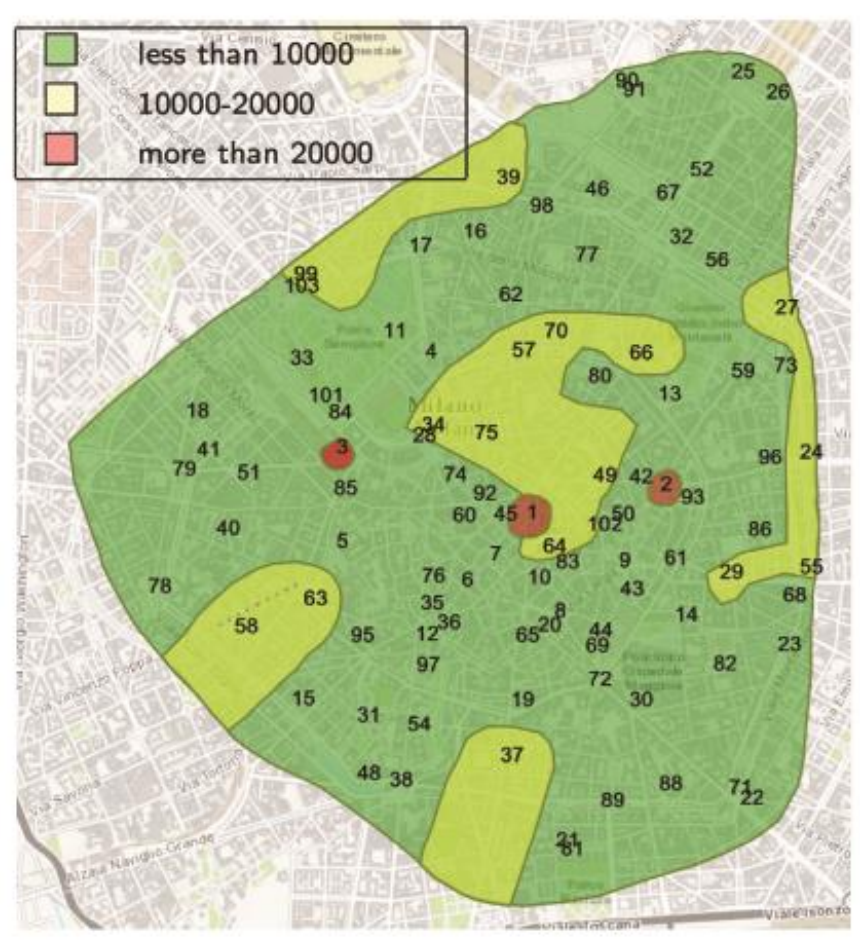

(a)

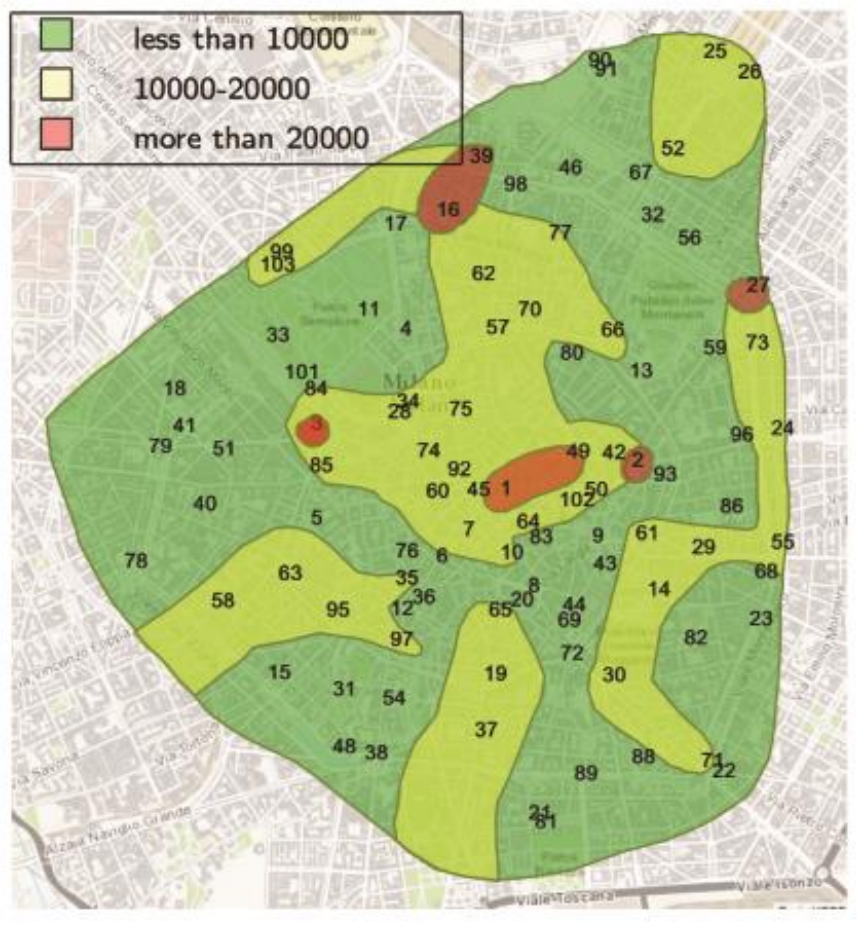

(b)

Figure 4: Distribution of docking stations and bike usage in the city centre of Milan (2010-2012). Numbers on the map are docking stations. Bike usage intensity is reported as the number of bike collected from docking stations in the period January 2010 - December 2010 (a), and September 2011- August 2012 (b) Locations of stations in the city centre have remained the same during the two periods - Source: Clear Channel Italy 


\section{ACCEPTED MANUSCRIPT}

(a)

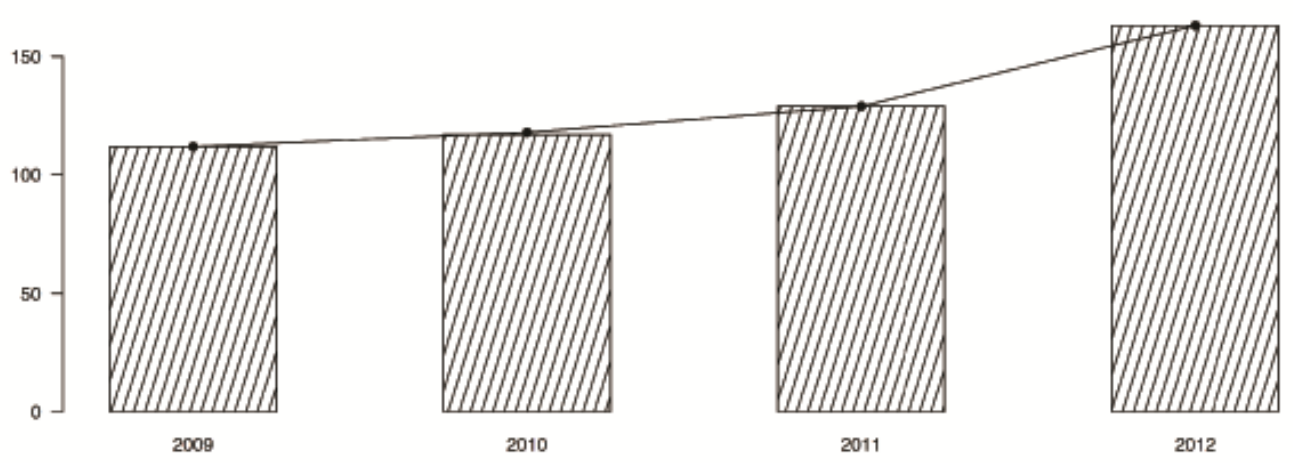

(b)

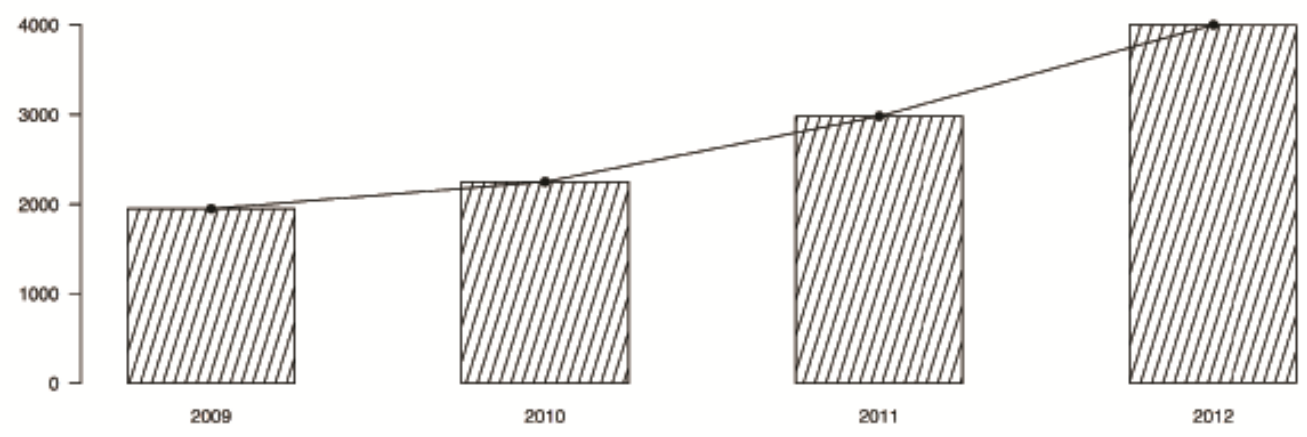

(c)

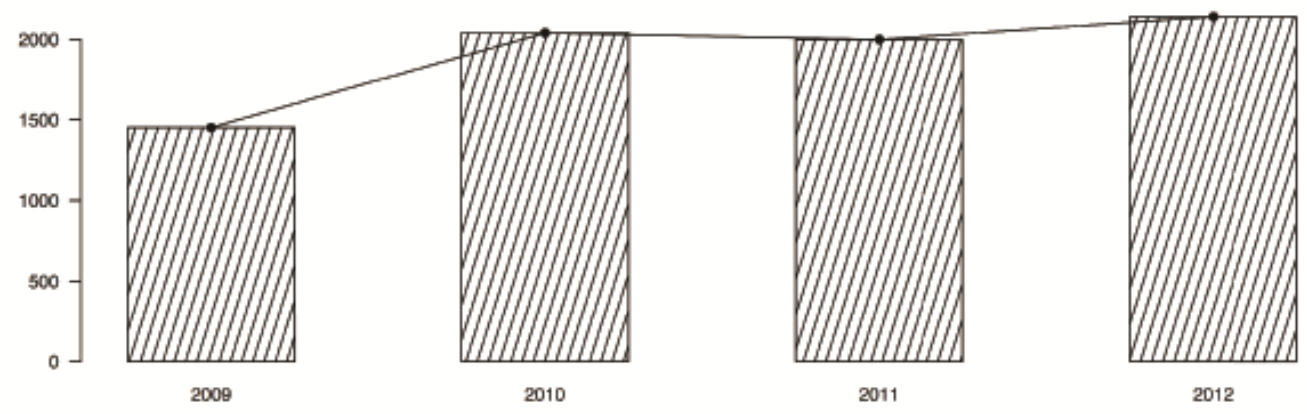

Figure 5: Number of docking stations (a), daily journeys (b) and fleet bikes (c) (2009-2012). Source: Clear Channel Italy 


\section{ACCEPTED MANUSCRIPT}

(a)

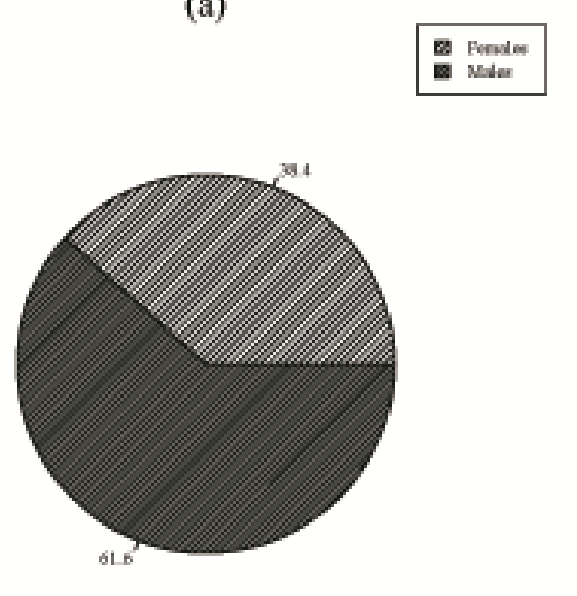

(c)

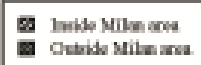

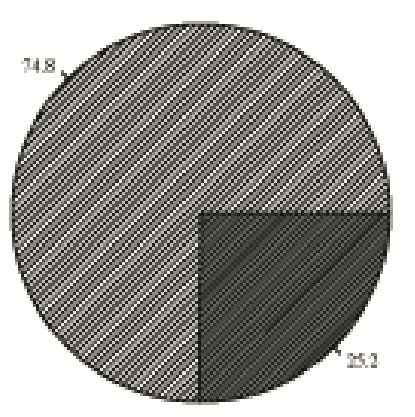

(b)

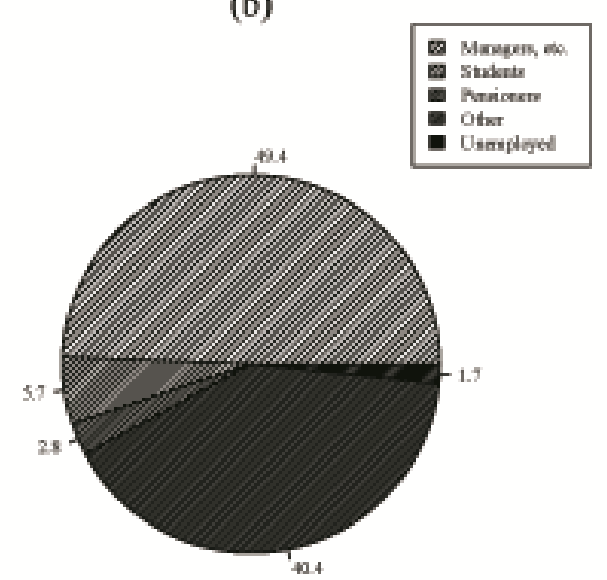

(d)
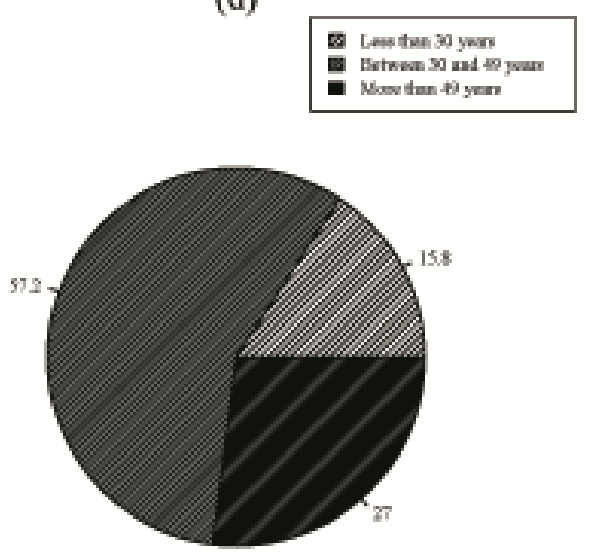

Figure 6: Respondents' distribution per gender (a), job type (b), commuters' residence (c) and age $(d)$ 


\section{ACCEPTED MANUSCRIPT}

(a)

Q Primaryllower scoondary

Upper soccendary

Tertiany

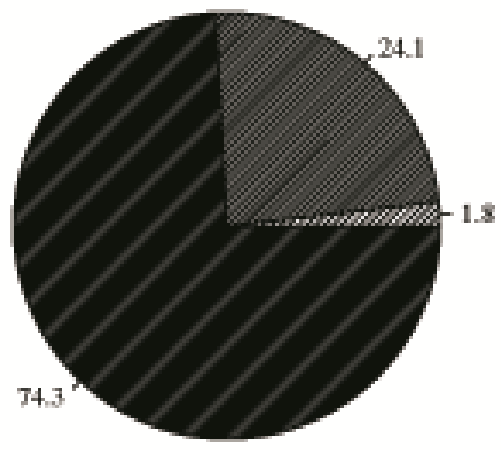

(b)

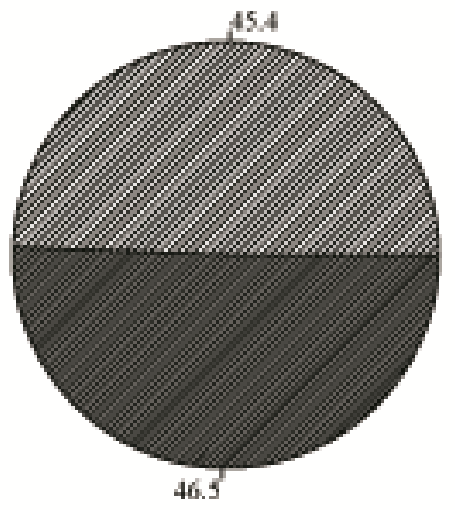

Figure 7: Education level (a) and marital status (b) among survey respondents 


\section{ACCEPTED MANUSCRIPT}

(a)

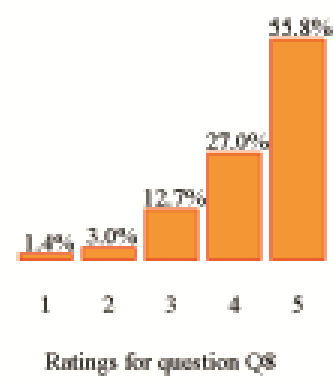

(d)

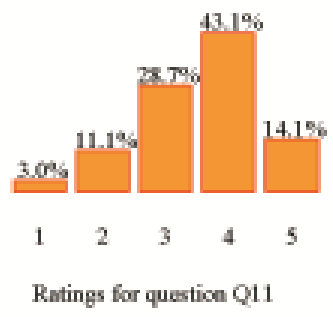

(g)

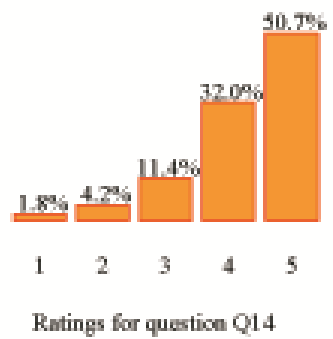

(b)

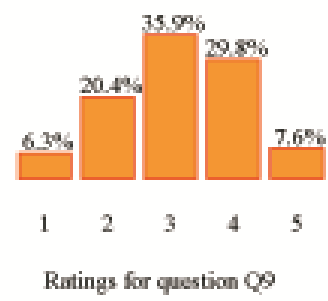

(e)

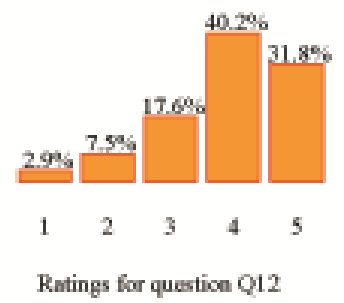

(c)

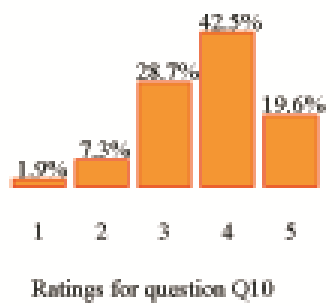

(f)

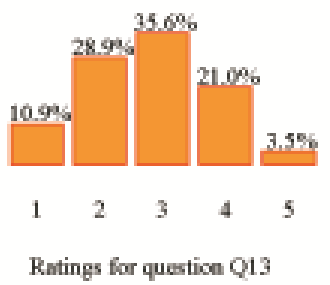

Figure 8: Distributions of responses in the satisfaction section of the questionnaire 


\section{ACCEPTED MANUSCRIPT}

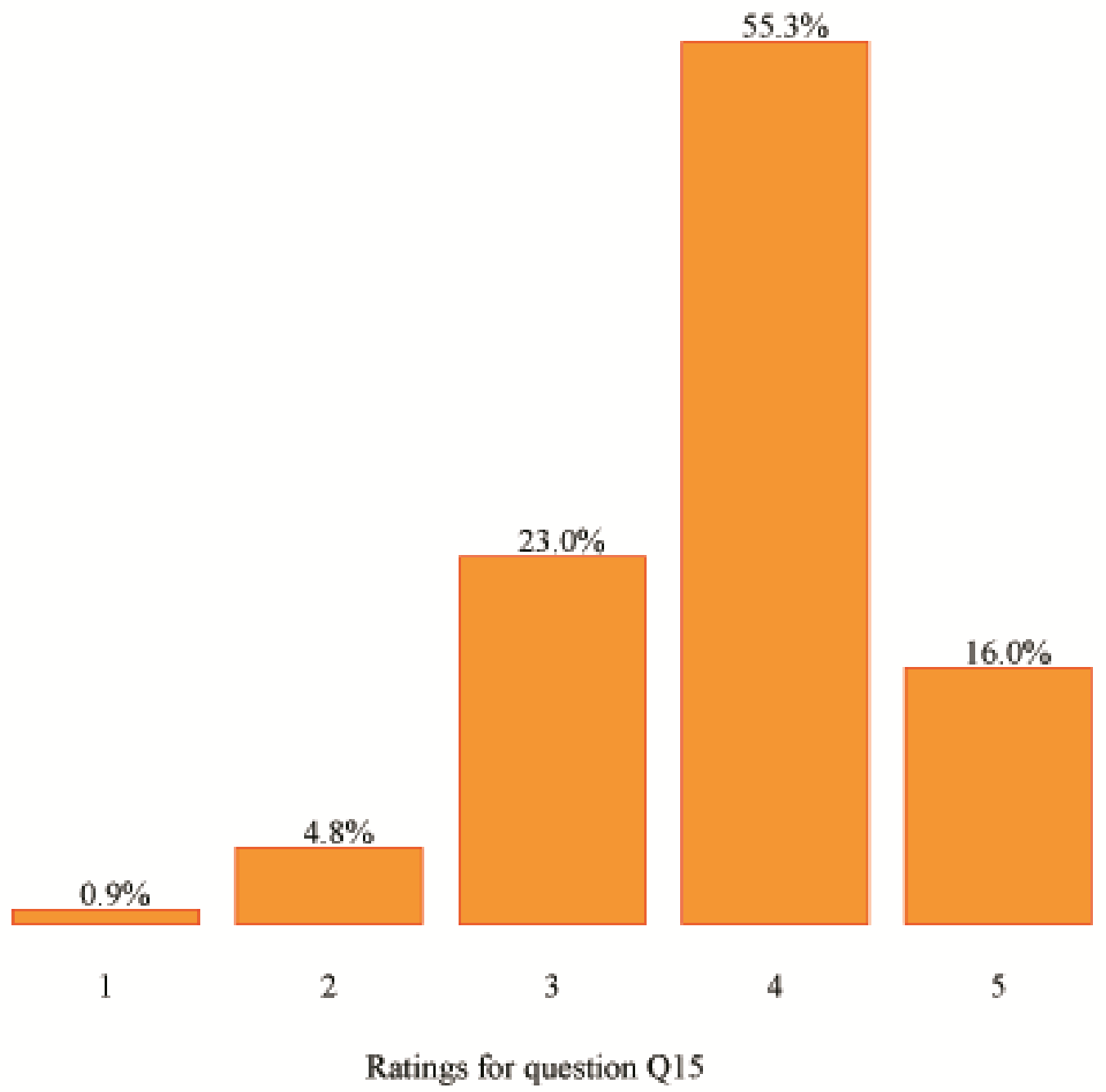

Figure 9: Overall satisfaction with the service 


\section{ACCEPTED MANUSCRIPT}

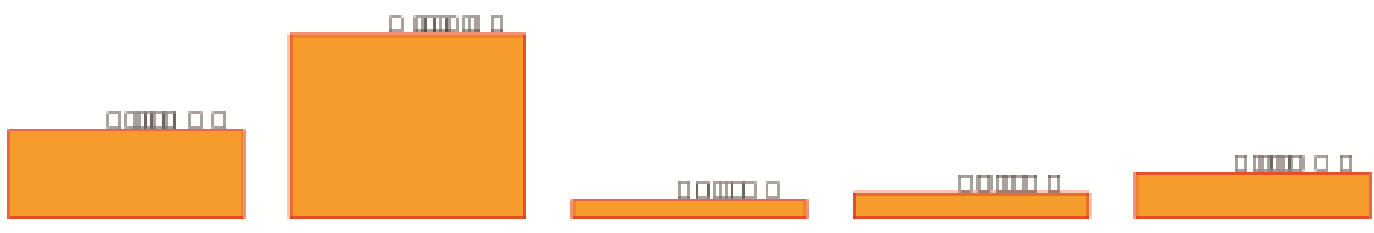

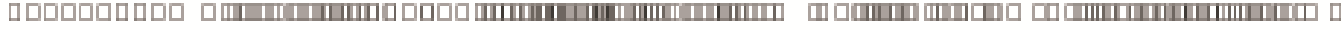

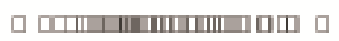

핌ㅁ
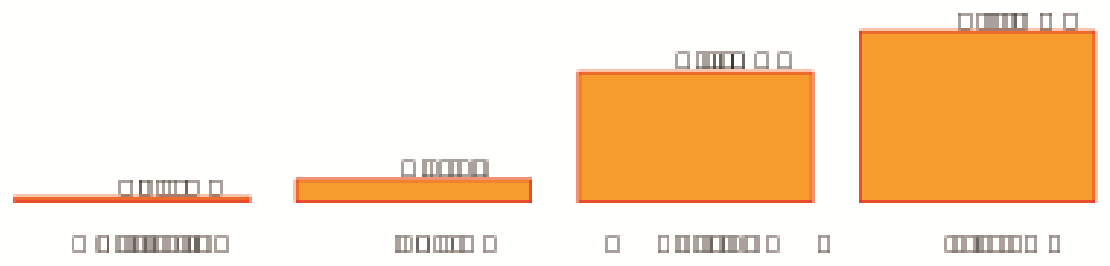

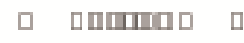

때m प

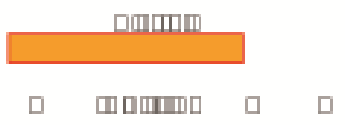

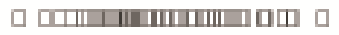

띰ㅁㅁ

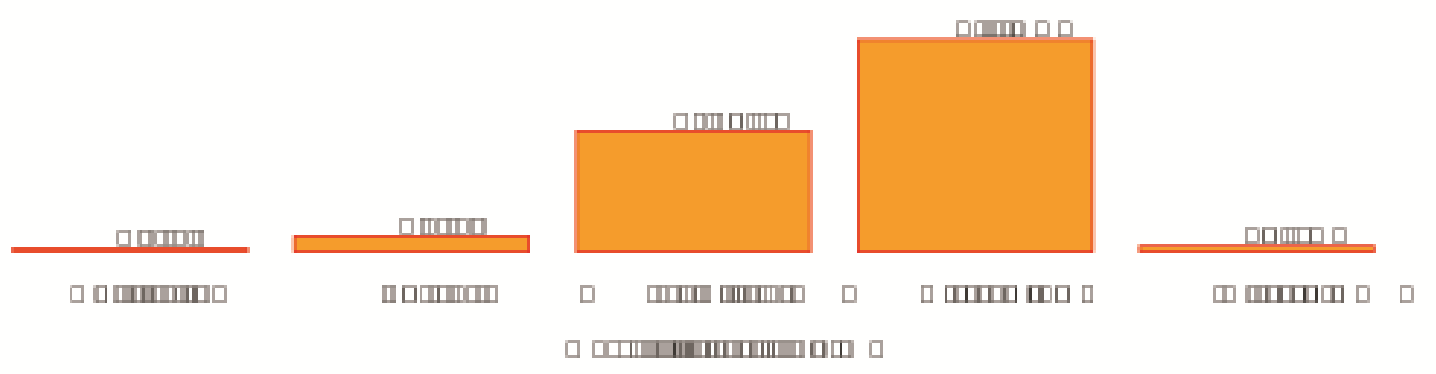

Figure 10: Usage of the service 


\section{ACCEPTED MANUSCRIPT}

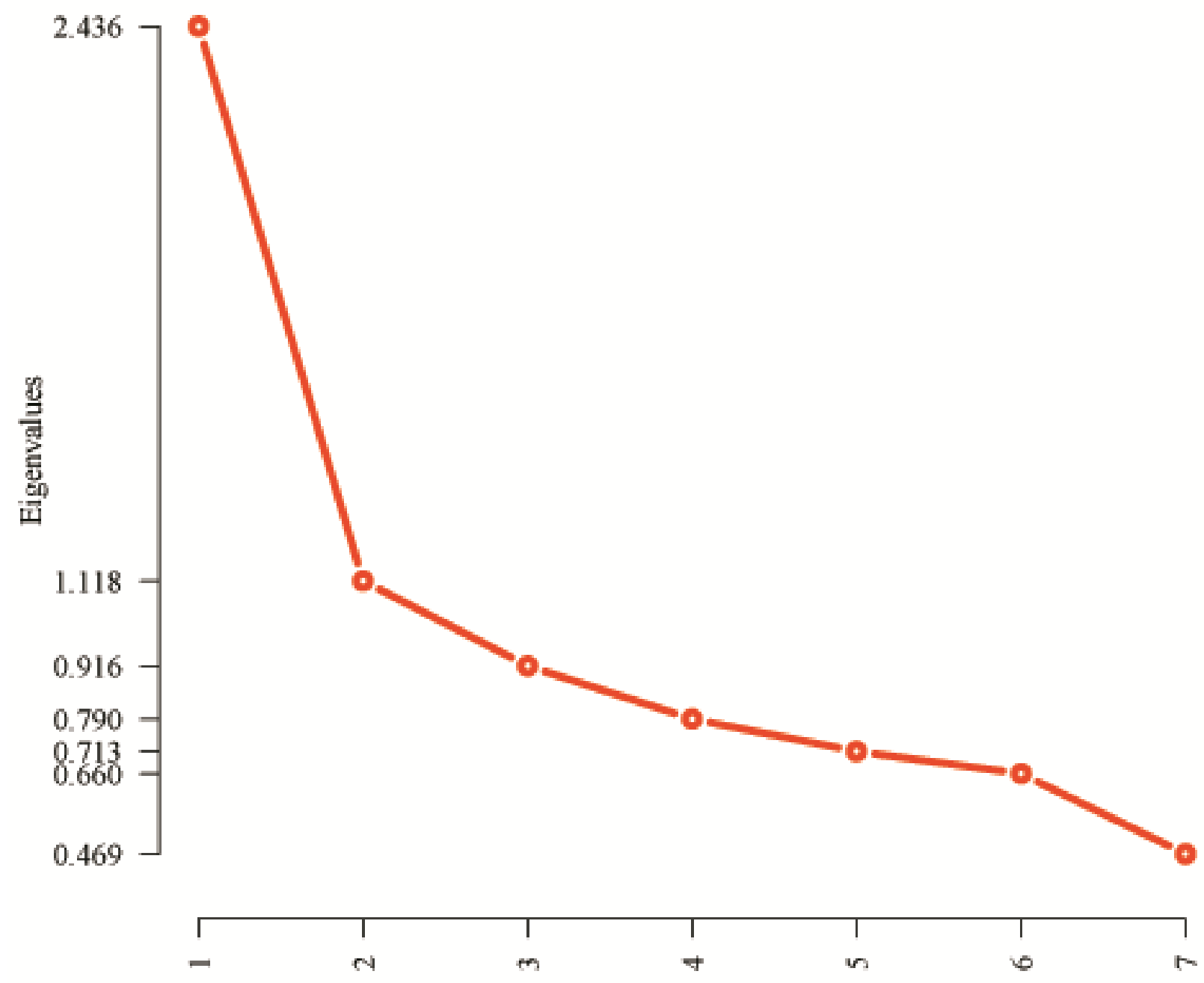

Component

Figure 11: Scree plot for the seven satisfaction variables 